\title{
Size, Shape and Flow Characterization of Ground Wood Chip and Ground Wood Pellet Particles
}

\author{
Hamid Rezaei ${ }^{1}$, C. Jim Lim ${ }^{1}$, Anthony Lau ${ }^{1}$, Shahab Sokhansanj ${ }^{1,2,1}$ \\ ${ }^{1}$ Chemical and Biological Engineering Department, University of British Columbia, Vancouver, \\ BC, Canada V6T 1 Z3 \\ ${ }^{2}$ Environmental Science Division, Oak Ridge National Laboratory, Oak Ridge, TN 37381, USA
}

\section{Introduction}

In recent years, the governments of Canada and the US adopted regulations to phase out coal-fired power plants by 2020 [1]. The power plants have devoted considerable resources to investigate the feasibility of utilizing biomass in order to reduce GHG emission. Woody biomass may be used in the form of wood chips or wood pellets [2-4]. Wood chips are mostly used in the fast pyrolysis process, whereas the wood pellet is a promising option for power boiler that is compatible with existing coal-firing facilities. The Atikokan and Thunder Bay power generation stations in Ontario, Canada are two examples of this replacement. Wood pellets have higher bulk density and more homogenous physical properties than wood chips [5, 6]. Wood pellets provide a more convenient form in terms of its handling, storage and feeding to the pyrolysis and combustion reactors $[4,7]$. Due to heat and mass transfer limitations, it is recommended to grind the pellets and large chips to particles that are smaller than $2 \mathrm{~mm}$ before feeding to a pyrolyzer or combustion chamber (power boiler) [8-13]. Wood pellets can be crushed by the pulverizer/roller mills, then the crushed powder can flow with the re-circulated hot gas in the pipe lines leading to the boilers. The size, shape and density of the biomass particles are known to affect the feeding

\footnotetext{
${ }^{1}$ Corresponding author:

Email address: $\underline{\text { shahab.sokhansanj@ubc.ca }}$
} 
system, flow properties, ignition temperature and kinetics of drying and thermal decomposition $[5,13-16]$.

Accurate, fast and inexpensive method of particle size analysis is desirable in the industries that handle particulate materials. The American Society of Agricultural and Biological Engineers (ASABE) developed mechanical sieving (S424.1, 2007) as a standard method to determine particle size distribution of biomass particles. Particle size distribution is obtained from the mass percent of particles retained on each sieve [17]. Particles pass through the sieves based on their width, whereas the length of the particles is ignored in the sieving process.

Biomass particles are mostly irregular and heterogeneous in size and shape [18]. Hence, two particles that pass through the same sieve may have different shapes, and the information obtained from the sieving process may not represent the size and shape characteristics of irregular-shaped biomass particles. Moreover, conducting the mechanical sieving for a number of samples is laborious [19], and the results may not be consistent [20].

Machine vision is an alternative approach to mechanical sieving. It is a more advanced technique to analyze the particle size and shape using image analysis [21]. Image analysis is a practical method to determine the actual dimensions and shape of single particles. It is not subjective and is repeatable over the same picture $[17,22]$. The shortcomings of image analysis is two dimensional analysis that omits the thickness of particles [20, 22]. Tannous et al. [18] suggested that picturing and measuring the thickness of a single Douglas fir particle is not practical and reliable, and assumed that the thickness of particles is $30 \%$ of its width.

Literature review indicates that a series of shape factors have been established to describe and evaluate the shape, form and structure of the particles. Shape factors provide quantitative information about the particle shape. Riley [23] stated the difficulty of 3D picturing of particles 
and introduced projected shape factors that are based on width, length, inscribed and circumscribed circles. Trottier et al. [24] defined shape factors using two or three dimensions of an individual particle and categorized the shape factors using four parameters: (1) dimensional ratios, (2) sphericity that indicates the deviation of a particle from a sphere/circle, (3) roundness and circularity that show angularity and sharpness of corners, and (4) roughness that shows surface structure. Fig. 1 illustrates the concept of various shape factors associated with a single wood particle.

Comprehensive information about the actual size, shape and density of biomass particles is crucially important in the industrial application that handle the particulate materials. Predicting the pressure drop across a bed of particles is one example of the applications [25]. Hoppers, screws, pneumatic transportation in pipelines and feeding systems in thermochemical conversion processes are other examples. Physical properties such as particle size, particle shape and surface roughness affect the flowability of biomass particles [18, 26-30]. Biomass particles are cohesive; they may stick together in a flowing stream of particles and cause a variety of flow issues. Bridging of biomass particles in the feeding system of a gasifier is a common industrial issue $[31,32]$.

The convenient analyses to conduct the flow characterization of minerals are mostly used for biomass particles, too [16, 18, 28, 29, 33-39]. Loose and tapped bulk densities represent a very quick method to estimate the flowability of particles [16, 35]. In the tapping process, particles re-arrange and change the packing condition [35]. A larger difference in the bulk density before and after the tapping process would imply the particles having more tendency to make a compact bulk. The dimensionless numbers "Hausner ratio (HR)"and "Carrcompressibility index (CCI)" quantify the increase in bulk density during the tapping process 
[18]. Bulk density can change with the size and shape of particles, the way that particles are arranged in the bulk and friction among the particles $[16,35,40]$. Wu et al. [26] showed that the bulk density of wood pellets is about 2-3 times that of wood chips, but they did not compare the bulk density of ground chip and ground pellet particles. Lam et al. [16] measured the bulk density of wheat straw and switchgrass as a function of physical attributes. Tapping the bulk compressed the longer particles more than shorter ones. The exact HR and CCI values depend strongly on the technique to determine the tapped bulk density, dropping height and the number of taps. Tannous et al. [18] showed that more tapping increases the tapped bulk density and the HR value. Thus, the published values of tapped bulk density are seldom comparable. Nevertheless, it is important to implement a consistent procedure of bulk density measurement to study the relative compressibility of different samples.

In a comprehensive fluidization review, Geldart et al. [41] showed that particles with HR less than 1.25 are free-flowable and easy to fluidize; particles with HR greater than 1.4 are cohesive and difficult to fluidize; and particles with HR values of 1.25-1.4 have partial properties of both groups. The CCI values between 5-15, 12-16, 18-21, and 23-28\% indicated excellent, good, fair, and poor flowability, respectively [18]. Tannous et al. [18] showed that HR and CCI values for Douglas fir particles decreased with decreasing particle size. By decreasing the particle size in the Sauter diameter range of $74-781 \mu \mathrm{m}$, HR and CCI values decreased from 1.85 to 1.32 and from 45.84 to 24.06 , respectively. Besides, smaller particles packed more with tapping and have poor flow properties than larger particles.

The angle of repose (AOR) is another test to study the relative flowability of samples. AOR is the angle of piled particles with respect to the horizontal surface, and it indicates the failure properties of particles under gravity [30]. AOR depends on the cohesiveness and 
stickiness of particles. In the literature, an increase in particle size is accompanied by a decrease in cohesiveness $[18,33]$. It is suggested that an AOR below $30^{\circ}$ shows good flowability, $30-45^{\circ}$ some cohesiveness, $45-55^{\circ}$ true cohesiveness and above $55^{\circ}$ very high cohesiveness [33]. In some other studies $[34,37,42], 40^{\circ}$ AOR was mentioned as the criteria for free flowability. Yet, there is no general agreement on the test procedure and the scale of AOR equipment. Geldart et al. [33] showed that variable amount of material may change AOR values. Wu et al. [26] worked with wood chips (lengths of 20, 40 and $100 \mathrm{~mm}$ ) and wood pellets (diameters of 6,8 and 12 $\mathrm{mm}$ ), and showed that wood pellets with AOR values of $35-38^{\circ}$ were more flowable than wood chips with AOR values of $44-46^{\circ}$. Wu et al. [26] did not measure the AOR of ground chip and ground pellet particles.

\section{Objectives}

The size, shape and density of the biomass particles affect their heat and mass transfer properties and flow properties. Due to the increasing application of ground chip particles in fast pyrolysis and crushed pellet particles in power boilers, the authors believe that further study is needed to determine their relative physical properties. Literature review shows that there is limited information on the comparative physical characterization of biomass particles in the form of ground chip versus ground pellet, in regard to their actual dimensions, shape, density and flow properties.

The objective of the current research was to study the size, shape, density and relative flow properties of ground pine chip and ground pine pellet particles. Digital image analysis was used to determine the dimensions, shape and some pre-defined shape factors. Compressibility analysis and the angle of repose test were used to evaluate the relative flow properties of the ground chip and ground pellet particles. The characterization results express a functional relationship between 
the physical properties and flowability of biomass particles. In particular, results for the dimensions and shape of biomass particles may be used to predict the pressure drop within a bed of ground particles [25]. The outcomes of this study will help towards using more precise input information in modeling the thermochemical conversion of single particles, as well as the design and optimization of the feeding system in power plants.

\section{Material and methods}

\subsection{Sample preparation}

Pine wood chips (30x30x5 mm) and commercially produced pine wood pellet (diameter of $6 \mathrm{~mm}$ and lengths of 12-24 mm) were supplied by Fiberco Inc. (North Vancouver, BC, Canada). Upon their delivery to the lab at UBC, the pine chips were dried in a THELCO laboratory PRECISION oven (Thermo Electron Corporation, Model 6550) at $80{ }^{\circ} \mathrm{C}$ down to $4-5 \%$ moisture content. After cooling, the dried chips were crushed in a hammer mill (Glen mills Inc., USA; Model 10HMBL) installed with four grinder screen sizes having circular perforations of 3.2, 6.3, 12.7 and $25.4 \mathrm{~mm}$. The received pellets had a moisture content of $5 \%$ and thus were not subjected to oven drying. Wood pellets were ground using the same hammer mill, but with three grinder screen sizes $(3.2,6.3$ and $12.7 \mathrm{~mm}$ perforations). The $25.4 \mathrm{~mm}$ grinder screen size was found to be too large for pellet grinding.

\subsection{Specific grinding energy}

Pine chips and pine pellets (5 $\mathrm{kg}$ each) were fed to the hammer mill using a vibratory feeder. The vibratory feeder provided a steady-state flow of material into the grinder. The rotating speed of the conveying belt in the feeder was set to feed the material during a 2-minute time interval, resulting in a feeding rate of $2.5 \mathrm{~kg} / \mathrm{min}$. The electricity line of the grinder was connected to a current meter. A data logging system recorded the current (ampere) by the time 
and converted to energy consumption $(\mathrm{J} / \mathrm{s})$. The consumed energy was averaged over the steadystate period and divided by the feeding rate $(\mathrm{kg} / \mathrm{s})$ to obtain and the specific grinding energy, $E_{g}$ $(\mathrm{kJ} / \mathrm{kg})$.

\subsection{Particle size distribution}

The hammer mill produces mixed ground particles. To determine the particle size distribution of each mixed ground sample, a tap sieve shaker (Ro-Tap RX 94) installed with different mesh sieves of $0.25,0.5,1,1.4,2,2.8$ and $6.3 \mathrm{~mm}$ was used. The meshes were arranged from the smallest to the largest mesh size. The shaker subjected the samples to oscillation and tapping for 10 minutes, following the procedure outlined in ASABE ANSI Standard S319.3. The mass retained on each sieve was weighed. The mean mass diameter of particles was calculated using equation (1) [18], where $x_{i}$ is the mass fraction of particles retained in the $i^{\text {th }}$ interval of mean diameter $\left(\mathrm{d}_{\mathrm{i}}\right)$ between two sieves.

$$
d_{s v}=\frac{1}{\sum x_{i} / d_{i}}
$$

\subsection{Image processing}

A representative $500 \mathrm{~g}$ of mixed ground materials were sieved using a $0.25 \mathrm{~mm}$ sieve. Igathinathane et al. [21, 43] suggested that very small particles $(<0.25 \mathrm{~mm})$ may agglomerate and do not give very accurate and reliable image analysis results. The retained particles were spread on a flat tray to a uniform depth. The samples were divided into 16 sub-parts. Using a spoon, a group of particles was picked randomly from the sample to be pictured. All ground pellet samples (ground using 3.2, 6.3 and $12.7 \mathrm{~mm}$ screens) and chip samples (ground using 3.2 and 6.3 mm screens) were observed and pictures were taken by a high resolution microscope. The maximum vision range of microscope was limited to $13-15 \mathrm{~mm}$. Therefore, the chip particles that 
were ground using 12.7 and $25.4 \mathrm{~mm}$ screens were pictured as a group of separated particles by a high resolution scanner connected to a computer. Pictures were analyzed using an image processing software (ImageJ ver. 1.49h, National Institutes of Health, USA). ImageJ is a simple and open source software to conduct the image analysis. It is a Java-based image processing software, developed by the US National Institute of Health (NIH).

Fig. 2 shows the full algorithm of image processing. ImageJ software was calibrated using a known-dimension kit to convert the pixel length to the millimeter. Image processing requires the binary images. In binary pictures, " 0 " is assigned to the background's pixels and " 1 " is assigned to the pixels inside the particle's border. Colored images are converted to the grey-scale images by a "RGB Stack" command. The grey-scale pictures were then converted into the binary images by proper thresholding. Igathinathane et al. [21] explained that using the same thresholding procedure may increase the halo effect around the particles and underestimate the particle's dimensions. Thus, a specific thresholding procedure was examined and implemented for each particle picture.

The dimensions of the ground particles were measured using the ellipse fitting technique in ImageJ software. The ellipse fitting plug-in fits the best ellipse on the particle's picture. ImageJ gives the major axis and minor axis of the ellipse that are representative of particle length (L) and particle width (W), respectively. Fig. 3 shows the dimensions measured in the image analysis of a single particle.

\subsection{Shape factors}

Using the outputs of image analysis, aspect ratio (AR), $W / d_{g s}$ and $L / d_{g s}$, sphericity, circularity and roundness are calculated. $d_{g s}(\mathrm{~mm})$ is the grinder screen opening size. The most 
common shape factor is the aspect ratio (AR), which is defined as the ratio of its width (W) over its length (L), equation (2) [18]. AR value ranges between " 0 " and " 1 ".

$$
A R=W / L
$$

Equivalent diameter is the diameter of a sphere that has the same volume-to-surface area ratio as the particle of interest. Owing to difficulty in measuring the surface area and volume of irregular-shape particles, a two dimensional equivalent spherical diameter $\left(d_{e q}\right)$ is suggested by Biagini et al. [3] in equation (3)

$d_{e q}=\left(\mathrm{L} \times \mathrm{W}^{2}\right)^{1 / 3}$

Sphericity $(\psi)$ of a particle indicates how closely the particle's shape looks like a sphere. Sphericity is defined as surface area of a sphere having the same volume of the particle $\left(S_{v}\right)$ divided by the actual surface area of the particle $\left(S_{s}\right)[24,44]$. A quicker method is proposed based on the two dimensional measurements of inscribed circle diameter $\left(d_{C I}\right)$ and circumscribed circle diameter $\left(d_{C C}\right)$ [23]. Inscribed circle is the largest circle that fits inside the particle's boundary. Circumscribed circle is smallest circle that encloses the particle's boundary. This technique determines the sphericity, as expressed in equation (4) [18]:

$\psi=\sqrt{d_{C I} / d_{C C}}$

Circularity $(\phi)$ is another shape factor that indicates angularity or sharpness of corners in a two dimensional analysis [18, 22, 24], as expressed in equation (5):

$\phi=4 \pi A / P^{2}$

where $\mathrm{A}$ and $\mathrm{P}$ are the projection area and perimeter of the particle, respectively. Image $\mathrm{J}$ counts the number of pixels inside the particle's boundary to determine area (A) and counts the number 
of pixels of particle's boundary to determine perimeter (P). Circularity is 1 for a sphere and 0.785 for a square. Similar to circularity, roundness is an indicator of angularity of a particle profile and shows the presence of sharp corners. The calculation of roundness based on individual curvature in the particle profile that is time consuming and laborious. However, a correlation, as expressed in equation (6), $[18,22]$ may be used to determine roundness:

Roundness $=4 \mathrm{~A} / \pi L^{2}$

Similar to circularity, roundness has the largest value of "1" for a circular object. It is important to mention that comparing the same shape factor obtained from different studies could be very confusing, since different concepts are assigned to the same shape factor. For example, Biagini et al. [3] defined roundness as (1/circularity) of what has been defined in this study. It is important to know what concept is addressed for each shape factor.

\subsection{Pycnometer density}

The solid density of a particle refers to the mass of the particle divided by the volume of the particle's skeleton $\left(\rho_{s}=m_{p} / V_{s}\right)$. In a gas pycnometer, helium or nitrogen gas can penetrate into the mesopores $(2-50 \mathrm{~nm})$, but their access to the micropores $(<2 \mathrm{~nm})$ and closed pores are limited. Therefore, the pycnometer density is a value in between particle density and solid density. Pycnometer density is the particle's mass divided by the total volume of solids and closed pores, $\rho_{p}=m_{p} /\left(\mathrm{V}_{s}+\mathrm{V}_{c p}\right)$ [18]. In this study, pycnometer density was measured using a nitrogen gas pycnometer, (Quantachrome Instruments, Boyton Beach, FL, USA; Model MVPD160-E). The unit has two chambers. The first chamber is the reference cell with volume of $11.67 \mathrm{~cm}^{3}$. The second chamber is the sample cell with volume of $29.42 \mathrm{~cm}^{3}$. The pressure of the reference cell was adjusted to around $117 \mathrm{kPa}$. The pressurized nitrogen diffused into the bed and 
the pores of particles in the sample cell. Then, the total volume of the skeleton and closed pores was calculated using the pressure difference measurement and ideal gas law. All density measurements were repeated five times to achieve the reproducibility of results.

\subsection{Bulk densities}

Loose bulk density refers to the mass of bulk of the sample divided by its aerated volume ( $\left.\rho_{l b}=m_{b} / V_{l b}\right)$. Constant mass of $200 \mathrm{~g}\left(m_{b}\right)$ of each ground sample was smoothly poured into a graduated cylinder. The volume of loose sample was recorded $\left(V_{l b}\right)$. Then, the vessel was dropped under its own mass from a height of $10 \mathrm{~cm}$ at different times. The volume of tapped particles was recorded in each 10-tap interval $\left(V_{t b}\right)$. The tapping process continued till no variation in bulk volume was observed. The tapped bulk density was then obtained via dividing the mass of the sample by the volume of tapped sample $\left(\rho_{t b}=m_{b} / V_{t b}\right)$. The Hausner ratio (HR) and Carr-compressibility index (CCI) were calculated using equations (7) and (8) [18, 23].

$$
\begin{aligned}
& H R=\frac{\rho_{t b}}{\rho_{l b}} \\
& C C I=\left(1-\frac{\rho_{l b}}{\rho_{t b}}\right) \times 100
\end{aligned}
$$

where $\rho_{l b}\left(\mathrm{~g} / \mathrm{cm}^{3}\right)$ and $\rho_{t b}\left(\mathrm{~g} / \mathrm{cm}^{3}\right)$ are loose and tapped bulk density, respectively, of the ground biomass particles.

\subsection{Angle of repose}

In this study, the Geldart apparatus was used to conduct the angle of repose analysis of ground biomass particles. Fig. 4 shows the schematic side view of the Geldart apparatus. The full procedure of measuring the angle of repose using the Geldart apparatus is explained in the literature $[33,34]$. In turn, a 50 g representative sample each of ground chip and ground pellet 
particles was weighed out. The ground materials were poured gently on a vibrating sheet that was installed with $45^{\circ}$ inclination. Due to the vibration, the particles were directed to a funnel, and dropped by gravity force onto a plate. A semi-cone pile was formed. Dashed line in Fig. 4 represents the pile of biomass particles. Because of the scattered shape of the pile edge, reading the height and radius of the pile was challenging. Therefore, the side view of the formed pile was pictured and the angle-measurement tool in the ImageJ software was used to measure the angle of repose.

\subsection{Development of empirical correlation}

Empirical correlations were developed to express a functional relationship for specific grinding energy $\left(E_{g}, \mathrm{~kJ} / \mathrm{kg}\right)$, Hausner ratio (HR) and Carr-compressibility index (CCI, \%) as a function of grinder screen size $\left(d_{g s}, \mathrm{~mm}\right)$. Based on literature review $[16,18,33]$, a power-law relation was used to fit the experimental data. The model parameters were determined using the Levenberg-Marquardt non-linear regression method. Coefficient of determination $\left(R^{2}\right)$, chisquare $\left(\chi^{2}\right)$ and root mean square error (RMSE) evaluated the fitting goodness of the proposed correlations. The values of $\chi^{2}$ and RMSE were calculated as follows [45, 46].

$$
\begin{gathered}
\chi^{2}=\frac{\sum_{i=1}^{N}\left(\text { Predicted }_{i}-\text { Experiment }_{i}\right)^{2}}{\mathrm{~N}-\mathrm{n}} \\
\mathrm{RMSE}=\sqrt{\frac{1}{\mathrm{~N}} \sum_{i=1}^{N}\left(\text { Predicted }_{i}-\text { Experiment }_{i}\right)^{2}}
\end{gathered}
$$

where $\mathrm{N}$ is number of experimental data and $\mathrm{n}$ is the number of parameters in the model. The predicted and experimental values of either $E_{g}$, HR or CCI are used in equations (9) and (10). 


\section{Results and discussion}

\subsection{Grinding energy}

The pine chips and pine pellets were ground using a hammer mill installed with grinder screen sizes of 3.2, 6.3, 12.7 and $25.4 \mathrm{~mm}$. Fig. 5 shows the specific grinding energy $(\mathrm{kJ} / \mathrm{kg})$ required to grind the pine chips and pine pellets using the different grinder screen sizes. These results demonstrated that grinding of pine chips consumed much more energy than pellets. For example, grinding chips used about 7 times more energy than grinding pellets with the $3.2 \mathrm{~mm}$ grinder screen. The specific grinding energy of chips declined drastically from $124 \mathrm{~kJ} / \mathrm{kg}$ for the $3.2 \mathrm{~mm}$ grinder screen to $28 \mathrm{~kJ} / \mathrm{kg}$ for the $25.4 \mathrm{~mm}$ grinder screen. By comparison, the specific grinding energy of pellets declined somewhat from $16 \mathrm{~kJ} / \mathrm{kg}$ for the $3.2 \mathrm{~mm}$ grinder screen to 12 $\mathrm{kJ} / \mathrm{kg}$ for the 12.7 grinder screen. Table 1 lists the corresponding empirical correlations for the specific grinding energy and the statistical parameters.

Grinding is an energy-consuming step in preparing feedstock for pyrolysis or combustion units. Since pellets are made from the previously-crushed particles, they were easier to grind. The significantly lower grinding energy required for pellets can constitute one major factor that affects the decision on whether ground chips or ground pellets shall be used in a thermochemical process such as pyrolysis.

\subsection{Particle size distribution}

Fig. 6 shows the particle size distribution (PSD) of ground chip and pellet particles obtained from mechanical sieving. The chip particles had a rather wide range of PSD, but the PSD of pellet particles had a narrower spread. This could be due to the fact that the internal particles of pellets were ground using a $3-5 \mathrm{~mm}$ grinder screen before the pelleting process $[18$, 47], and pellet particles were less sensitive to the grinder screen size. The mass-averaged 
diameter of ground chip particles were $0.58,0.87,1.59$ and $2.29 \mathrm{~mm}$ for grinder screens of 3.2, 6.3, 12.7 and $25.4 \mathrm{~mm}$, respectively. The mass-averaged diameters of ground pellet particles were $0.50,0.56$ and $0.64 \mathrm{~mm}$ for grinder screens of 3.2, 6.3 and $12.7 \mathrm{~mm}$, respectively.

The $3.2 \mathrm{~mm}$ grinder screen appears to produce the chip and pellet particles with similar PSD. Most of the particles were retained on the 0.25 and $0.5 \mathrm{~mm}$ sieves. Furthermore, about 36$39 \%$ of chips and pellet particles ground with the $3.2 \mathrm{~mm}$ grinder screen passed through the 0.5 $\mathrm{mm}$ sieve. Table 2 lists the fraction of particles that passed through the 1 and $2 \mathrm{~mm}$ sieves. Several researchers recommended the size of biomass particles should be reduced to less than 2 $\mathrm{mm}$ in order to minimize the biochar yield during pyrolysis/combustion [8-13]. The PSD output shows that more than $88 \%$ pellet particles were smaller than $2 \mathrm{~mm}$. Nevertheless, grinding wood chip with only grinder screens that are smaller than $6 \mathrm{~mm}$ gives an appropriate PSD for thermal conversion. It shall be noted that a more accurate size analysis technique is required to measure the real size of particles and characterize the shape of ground particles.

\subsection{Particle dimensions and shape}

The output of single particle shape analysis showed that the actual dimensions and shape of ground chip and pellet particles were not similar. The visually observed differences are shown in Fig. 3 and Fig. 7. Ground chip particles had rectangular shape. As shown in Table 2, the low values of the various shape factors - sphericity $(0.44-0.45)$, circularity $(0.27-0.33)$ and roundness (0.21-0.25) imply that the ground chip particles were far from spherical. Chip particles had a small aspect ratio (AR) of 0.21-0.22. Single chip particles were uniform in their width alongside their length. In contrast, ground pellet particles were completely irregular in shape, though pellet particles appear more spherical. Sphericity and roundness of pellet particles were in the range of $0.70-0.73$ and $0.62-0.70$, respectively. Thus, the sphericity and roundness of pellet particles were 
about 1.5-2.0 and 3.0-3.5 times those of chip particles, respectively. The average aspect ratio of pellet particles was $0.60-0.64$; this is also about 3 times that of chip particles.

Ground chip and ground pellet particles were also different in terms of their dimensions. Inspection of the $W / d_{g s}$ and $L / d_{g s}$ shape factors in Table 2 reveals that the dimensions (width W, length L) of the pellet particles were smaller than the grinder screen opening size $\left(d_{g s}\right)$. Whereas, the lengths of chip particles were always greater than the grinder screen opening size. Fig. 8 demonstrates that width and length of both chip and pellet particles increased linearly with the grinder screen opening size $\left(d_{g s}\right)$. Empirical correlations have been developed to express the average width and length of ground particles as a function of grinder screen size, as presented in Table 3.

Even though the mechanical sieving process separates the particles based on their width, Fig. 8 shows that the mass-averaged diameter $\left(d_{s v}\right)$ obtained from mechanical sieving was always less than the actual width of particles. Apparently, mechanical sieving underestimated the actual width of particles, since the $d_{s v}$ was about $50 \%$ of particle width for the chip particles and $33 \%$ of width for the pellet particles. In despite of mass-averaged diameter, equivalent particle size $\left(d_{e q}\right)$ was always a value between width and length. Linear empirical correlations that are presented in Table 3 show the variations of average width (W), average length (L), massaveraged diameter $\left(d_{s v}\right)$ and equivalent spherical diameter $\left(d_{e q}\right)$ with grinder screen size $\left(d_{g s}\right)$.

\subsection{Pycnometer density}

Table 4 lists the pycnometer density values of ground chip and pellet particles. The pycnometer density increased with the level of grinding. The structure of the particles broke due to size reduction, thus opening the closed pores and increasing the number of accessible pores for 
the pycnometer gas to penetrate. The density of ground chip particles increased from 1.05 to 1.33 $\mathrm{g} / \mathrm{cm}^{3}$ when the grinder screen size was changed from 25.4 to $3.2 \mathrm{~mm}$. The pycnometer density of ground pellet particles only increased slightly from 1.40 to $1.43 \mathrm{~g} / \mathrm{cm}^{3}$ when the grinder screen size was changed from 12.7 to $3.2 \mathrm{~mm}$.

There were two observed differences associated with the pycnometer densities of chip and pellet particles. Firstly, the grinding operation affected the density of chip particles more than pellet particles. This could be attributed to the fact that the internal particles of pellet were ground before pelleting and further grinding of pellets did not change the pycnometer density significantly. Secondly, the higher pycnometer density of ground pellet particles could result from the structural transformation in the densification process. During pelleting, the applied force smashed the cellular structure of the fibers and reduced the pore volume of the particles. Fig. 9 shows the SEM images of a single ground chip and ground pellet particle.

\subsection{Flow characterization}

Table 4 lists the loose and tapped bulk densities of chip and pellet particle. The loose bulk density of both chip and pellet particles increased with increasing particle size. The bulk density of pellet particles is greater than chip particles, and two reasons can explain this observation. Single pellet particles are denser than chip particles. Besides, chip particles have a much lower aspect ratio $(\mathrm{W} / \mathrm{L})$ and their random settlement makes a more porous bulk. During the tapping process, the bulk density of particles increased as expected. Smaller particles required more tapping to reach to their final compaction. Ground chip particles ground with the 3.2 and $6.3 \mathrm{~mm}$ grinder screens became increasingly compact until about 70-80 taps were made, while larger chip particles reached their stable compaction after about 20 taps. All ground pellet samples 
reached their final compaction state after 30-40 taps. Eventually, the tapped bulk density after 100 taps was used to calculate the HR and CCI.

As depicted in Fig. 10, the HR and CCI values decreased with particle size. Larger particles had less tendency to make a compact bulk. Smaller particles were able to fill very small pores in the bulk and increase the density. The same trend was also observed for the pellet particles, though the variation in the compressibility of pellet particles was less than chip particles. This is most probably due to the very similar particle size distribution of pellet particles ground with different grinder screens.

Particle size was not the only factor that affect the compressibility. Chip and pellet particles subject to the $3.2 \mathrm{~mm}$ grinder screen had similar PSD. Yet, the chip particles compacted by $50 \%$ which is significantly more than the pellet particles which compacted by $26 \%$. The level of compression seems to be highly dependent on the shape of the particles. Pellet particles were more spherical, as compared to the needle-shaped chip particles. Greater length appears to promote the compression of the particles. The effect of particle shape was not observed just for the particles having the same size and particle size distribution. Upon comparing the particle size, particle shape and compaction of chip and pellet particles ground with 6.3 and $12.7 \mathrm{~mm}$ grinder screens, particle shape was confirmed to be more important than particle size in tapping compressibility. Grinder screen sizes of 6.3 and $12.7 \mathrm{~mm}$ made pellet particles much smaller than chip particles; but still the pellet particles had less compaction and significantly smaller HR and CCI values. Empirical correlations as previously shown in Table 1 were developed to predict the HR and CCI values for the ground chip and pellet particles as a function of grinder screen $\operatorname{size}\left(d_{g s}\right)$. 
The biomass particles are cohesive and have interaction among each other. The angle of repose (AOR) indicates the relative cohesiveness of the particles under a normal force [30]. Results are shown in Table 4 and Fig. 11. The AOR of chip particles was seen to decrease from $61.0^{\circ}$ to $45.9^{\circ}$ when grinder screen was changed from 3.2 to $25.4 \mathrm{~mm}$. It is in agreement with the literature that reported an increase in particle size is accompanied by a decrease in cohesiveness and hence AOR [18, 33]. Small particles have higher specific surface area that boosts the contact and cohesiveness among the particles. Due to very similar PSD of pellet particles, the AOR values of pellet particles were practically independent of grinder screen size. Similar to the results pertinent to compressibility, the effect of particle shape was more significant than particle size. Chip and pellet particles ground with $3.2 \mathrm{~mm}$ grinder screen had AOR values of $61.0^{\circ}$ and $48.0^{\circ}$, respectively. The difference between AOR of chip and pellet particles having the same PSD could be explained by their different particle shapes. The same extent of AOR reduction was observed when the grinder screen was switched from the smallest size of $3.2 \mathrm{~mm}$ to the largest size of $25.4 \mathrm{~mm}$ for chip grinding.

\section{Conclusions}

In this study, the size, shape and flow properties of ground pine chip particles and ground pine pellet particles were characterized. To produce the same size of particles, the wood chips took about 7 times more energy to be ground than wood pellets. Ground pellet particles were smaller and had a narrower particle size distribution than ground chip particles. More than $88 \%$ of all ground pellet samples pass through a $2 \mathrm{~mm}$ sieve that makes the ground pellet appropriate for thermal conversion processes. Wood chips need to be ground with grinder screens of smaller than $6 \mathrm{~mm}$ to produce an appropriate PSD for thermal conversion. 
Pelletization reduced the variability in size distribution, particle shape and flow properties of ground particles. Pellet particles are more circular shape and have the aspect ratios (W/L) of about 3 times of long and narrow chip particles. Needle-shape chip particles cause the bulk to compress more. Angle of repose tests showed that pellet particles are less cohesive and flow easier than chip particles. Small ground chip particles may cause flow issues in a bulk of the particles. Flow characterization showed that the effect of particle shape on flow properties of particles is more than the particle size.

\section{Acknowledgements}

This work was supported by the Biofuel Network Canada, BFN (grant number: 11R08764) and Natural Sciences and Engineering Research Council of Canada. The authors also gratefully acknowledge contribution of Fibreco Inc. for providing the wood chip and wood pellet samples.

\section{Nomenclature}

A

AR

$d_{C I}$

$d_{C C}$

$d_{e q}$

$d_{i}$

$d_{s v}$

$d_{g s}$

$E_{g}$

$\mathrm{L}$

$\mathrm{m}_{\mathrm{b}}$

$\mathrm{m}_{\mathrm{p}}$

$P$

$\mathrm{S}_{\mathrm{S}}$

$\mathrm{S}_{\mathrm{v}}$

$\mathrm{V}_{\mathrm{lb}}$

$\mathrm{V}_{\mathrm{tb}}$
Area of projected particle, $\mathrm{mm}^{2}$

Aspect ratio of particle

Inscribed circle diameter, $\mathrm{mm}$

Circumscribed circle diameter, $\mathrm{mm}$

Equivalent spherical diameter, $\mathrm{mm}$

Mean diameter between two sieves, $\mathrm{mm}$

Mass-averaged particle size, $\mathrm{mm}$

Grinder screen size, mm

Specific grinding energy, $\mathrm{kJ} / \mathrm{kg}$

Particle length, $\mathrm{mm}$

Mass of bulk of particles, $g$

Mass of particle, $g$

Perimeter of projected particle, $\mathrm{mm}$

Surface area of a sphere having the same volume as the particle, $\mathrm{mm}^{2}$

Actual surface area of particle, $\mathrm{mm}^{2}$

Volume of loose bulk of particles, $\mathrm{cm}^{3}$

Volume of tapped bulk of particles, $\mathrm{cm}^{3}$ 


$\mathrm{V}_{\mathrm{p}}$
$\mathrm{V}_{\mathrm{s}}$
$\mathrm{V}_{\mathrm{cp}}$
$\mathrm{V}_{\mathrm{op}}$
$\mathrm{W}$
$\mathrm{x}_{\mathrm{i}}$

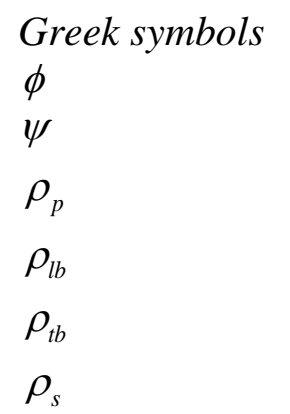

Total volume of particle, $\mathrm{cm}^{3}$

Volume of solid part of particle, $\mathrm{cm}^{3}$

Volume of closed pores of particle, $\mathrm{cm}^{3}$

Volume of open pores of particle, $\mathrm{cm}^{3}$

Particle width, mm

Mass fraction of particles retained in the $\mathrm{i}^{\text {th }}$ sieve interval

Circularity

Sphericity

Pycnometer density, $\mathrm{g} / \mathrm{cm}^{3}$

Loose bulk density, $\mathrm{g} / \mathrm{cm}^{3}$

Tapped bulk density, $\mathrm{g} / \mathrm{cm}^{3}$

Solid density, $\mathrm{g} / \mathrm{cm}^{3}$

\section{References}

[1] L. Marshall, D. Gaudry, The Application of the Dedicated Milling Concept for 100\% Wood Firing at Atikokan Generating Station, Ontario Power Generation, Atikokan GS OPG, 2011.

[2] T.R. Carlson, G.A. Tompsett, W.C. Conner, G.W. Huber, Aromatic Production from Catalytic Fast Pyrolysis of Biomass-Derived Feedstocks, Top. Catal., 52 (2009) 241-252.

[3] E. Biagini, P. Narducci, L. Tognotti, Size and structural characterization of lignin-cellulosic fuels after the rapid devolatilization, Fuel, 87 (2008) 177-186.

[4] F. Miccio, D. Barletta, M. Poletto, Flow properties and arching behavior of biomass particulate solids, Powder Technology, 235 (2013) 312-321.

[5] P.D. Jensen, M. Temmerman, S. Westborg, Internal particle size distribution of biofuel pellets, Fuel, 90 (2011) 980-986.

[6] Z. Tooyserkani, L. Kumar, S. Sokhansanj, J. Saddler, X.T. Bi, C.J. Lim, A. Lau, S. Melin, SO2-catalyzed steam pretreatment enhances the strength and stability of softwood pellets, Bioresour. Technol., 130 (2013) 59-68.

[7] C. Erlich, E. Björnbom, D. Bolado, M. Giner, T.H. Fransson, Pyrolysis and gasification of pellets from sugar cane bagasse and wood, Fuel, 85 (2006) 1535-1540.

[8] A.V. Bridgwater, G.V.C. Peacocke, Fast pyrolysis processes for biomass, Renewable Sustainable Energy Rev., 4 (2000) 1-73.

[9] A. Demirbas, Effects of temperature and particle size on bio-char yield from pyrolysis of agricultural residues, J. Anal. Appl. Pyrolysis, 72 (2004) 243-248.

[10] S. Czernik, A.V. Bridgwater, Overview of Applications of Biomass Fast Pyrolysis Oil, Energy Fuels, 18 (2004) 590-598.

[11] A.V. Bridgwater, Review of fast pyrolysis of biomass and product upgrading, Biomass and Bioenergy, 38 (2012) 68-94.

[12] W.N.R.W. Isahak, M.W.M. Hisham, M.A. Yarmo, T.-y. Yun Hin, A review on bio-oil production from biomass by using pyrolysis method, Renewable Sustainable Energy Rev., 16 (2012) 5910-5923. 
[13] M. NikAzar, M.R. Hajaligol, M. Sohrabi, B. Dabir, Effects of heating rate and particle size on the products yields from rapid pyrolysis of beech-wood, Fuel Sci. Technol. Int., 14 (1996) 479-502.

[14] D.S. Scott, J. Piskorz, The Continuous Flash Pyrolysis of Biomass, Can. J. Chem. Eng., 62 (1984) 404-412.

[15] L. Baxter, Biomass-coal co-combustion: opportunity for affordable renewable energy, Fuel, 84 (2005) 1295-1302.

[16] P.S. Lam, S. Sokhansanj, X. Bi, C.J. Lim, L.J. Naimi, M. Hoque, S. Mani, A.R. Womac, Bulk density of wet and dry wheat straw and switch grass particles, Appl. Eng. Agric., 24 (2008) 351-358.

[17] C. Igathinathane, L.O. Pordesimo, E.P. Columbus, W.D. Batchelor, S. Sokhansanj, Sieveless particle size distribution analysis of particulate materials through computer vision, Comput. Electron. Agric., 66 (2009) 147-158.

[18] K. Tannous, P.S. Lam, S. Sokhansanj, J.R. Grace, Physical Properties for Flow Characterization of Ground Biomass from Douglas Fir Wood, Particulate Science and Technology, 31 (2012) 291-300.

[19] S.J. Blott, K. Pye, GRADISTAT: a grain size distribution and statistics package for the analysis of unconsolidated sediments, Earth Surface Processes and Landforms, 26 (2001) 12371248.

[20] S. Paulrud, J.E. Mattsson, C. Nilsson, Particle and handling characteristics of wood fuel powder: effects of different mills, Fuel Processing Technology, 76 (2002) 23-39.

[21] C. Igathinathane, S. Melin, S. Sokhansanj, X. Bi, C.J. Lim, L.O. Pordesimo, E.P. Columbus, Machine vision based particle size and size distribution determination of airborne dust particles of wood and bark pellets, Powder Technology, 196 (2009) 202-212.

[22] J.M. Rodriguez, T. Edeskär, S. Knutsson, Particle shape quantities and measurement Techniques-A review, Electronic Journal of Geotechnical Engineering, 18 (2013) 169-198. [23] N.A. Riley, Projection sphericity, Journal of Sediment Research, 11 (1942) 94-95.

[24] R. Trottier, S. Dhodapkar, A Guide to Characterizing Particle Size and Shape, Chem. Eng. Prog., AIChE, 2014, pp. 36-46.

[25] I. Grubecki, Airflow versus pressure drop for a mixture of bulk wood chips and bark at different moisture contents, Biosystems Engineering, 139 (2015) 100-110.

[26] M.R. Wu, D.L. Schott, G. Lodewijks, Physical properties of solid biomass, Biomass and Bioenergy, 35 (2011) 2093-2105.

[27] A.G. Athanassiadis, M.Z. Miskin, P. Kaplan, N. Rodenberg, S.H. Lee, J. Merritt, E. Brown, J. Amend, H. Lipson, H.M. Jaeger, Particle shape effects on the stress response of granular packings, Soft Matter, 10 (2014) 48-59.

[28] Z. Guo, X. Chen, H. Liu, Q. Guo, X. Guo, H. Lu, Theoretical and experimental investigation on angle of repose of biomass-coal blends, Fuel, 116 (2014) 131-139.

[29] Z. Guo, X. Chen, Y. Xu, H. Liu, Study of flow characteristics of biomass and biomass-coal blends, Fuel, 141 (2015) 207-213.

[30] Z. Guo, X. Chen, Y. Xu, H. Liu, Effect of granular shape on angle of internal friction of binary granular system, Fuel, 150 (2015) 298-304.

[31] Y. Ueki, T. Torigoe, H. Ono, R. Yoshiie, J.H. Kihedu, I. Naruse, Gasification characteristics of woody biomass in the packed bed reactor, Proceedings of the Combustion Institute, 33 (2011) 1795-1800. 
[32] J. Dai, J. Saayman, J.R. Grace, N. Ellis, Gasification of Woody Biomass, Annual Review of Chemical and Biomolecular Engineering, 6 (2015) 77-99.

[33] D. Geldart, E.C. Abdullah, A. Hassanpour, L.C. Nwoke, I. Wouters, Characterization of powder flowability using measurement of angle of repose, China Particuology, 4 (2006) 104107.

[34] D. Geldart, E.C. Abdullah, A. Verlinden, Characterisation of dry powders, Powder Technology, 190 (2009) 70-74.

[35] E.C. Abdullah, D. Geldart, The use of bulk density measurements as flowability indicators, Powder Technology, 102 (1999) 151-165.

[36] N. Chevanan, A.R. Womac, V.S.P. Bitra, D.C. Yoder, S. Sokhansanj, Flowability parameters for chopped switchgrass, wheat straw and corn stover, Powder Technology, 193 (2009) 79-86.

[37] M.V.V. Antequera, A.M. Ruiz, M.C.M. Perales, N.M. Munoz, M.R.J.-C. Ballesteros, Evaluation of an adequate method of estimating flowability according to powder characteristics, Int. J. Pharm., 103 (1994) 155-161.

[38] P. Chen, Z. Yuan, X. Shen, Y. Zhang, Flow properties of three fuel powders, Particuology, 10 (2012) 438-443.

[39] X. Fu, D. Huck, L. Makein, B. Armstrong, U. Willen, T. Freeman, Effect of particle shape and size on flow properties of lactose powders, Particuology, 10 (2012) 203-208.

[40] G.L. Eriksson, C. Boman, U. Bergsten, D. Bergström, Fuel Characterization of Pellet Chips, Forest Products Journal, 61 (2011) 143-148.

[41] D. Geldart, Types of gas fluidization, Powder Technology, 7 (1973) 285-292.

[42] R. Brown, J.C. Richards, Principles of powder mechanics, Pergamon Press, Oxford, 1970.

[43] C. Igathinathane, L.O. Pordesimo, E.P. Columbus, W.D. Batchelor, S.R. Methuku, Shape identification and particles size distribution from basic shape parameters using ImageJ, Comput. Electron. Agric., 63 (2008) 168-182.

[44] W. Hakon, Volume, Shape, and Roundness of Quartz Particles, The Journal of Geology, 43 (1935) 250-280.

[45] D. Chen, Y. Zhang, X. Zhu, Drying Kinetics of Rice Straw under Isothermal and

Nonisothermal Conditions: A Comparative Study by Thermogravimetric Analysis, Energy Fuels, 26 (2012) 4189-4194.

[46] C. Junmeng, C. Siyu, Determination of Drying Kinetics for Biomass by Thermogravimetric Analysis under Nonisothermal Condition, Drying Technology, 26 (2008) 1464-1468.

[47] J.S. Tumuluru, K.G. Cafferty, K.L. Kenny, Techno-economic Analysis of Conventional, High Moisture Pelletization and Briquetting Process, ASABE and CSBE/SCGAB Annual International MeetingMontreal, Quebec Canada, 2014. 


\section{Tables}

\section{Table 1}

Empirical correlations of specific grinding energy consumption $\left(E_{g}, \mathrm{~kJ} / \mathrm{kg}\right)$, Hausner ratio (HR) and Carr-compressibility index $(\mathrm{CCI}$, $\%)$ of ground chip and ground pellet particles as a function of grinder screen size $\left(d_{g s}, \mathrm{~mm}\right)$.

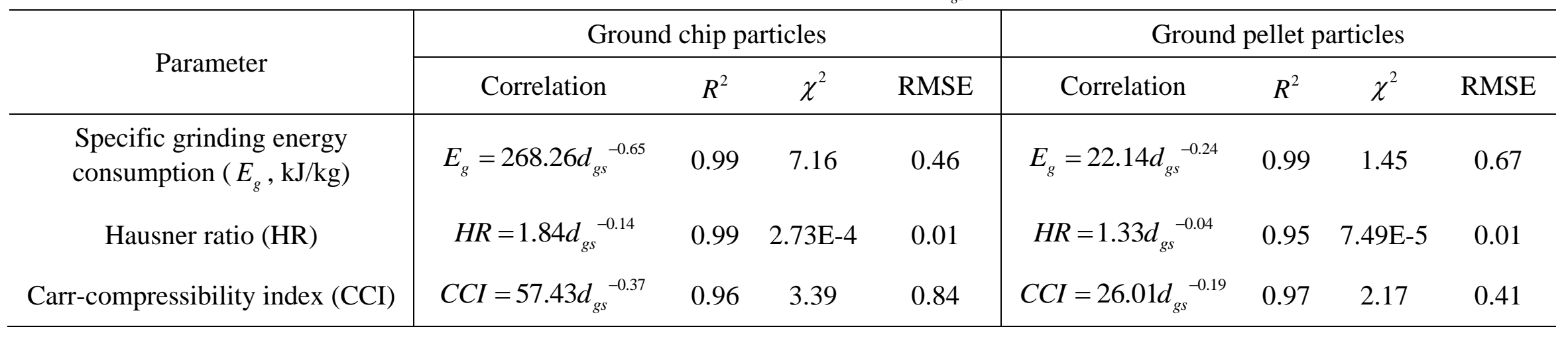


Table 2

Size and shape properties of ground chip and ground pellet particles using mechanical sieving and image analysis (mean \pm standard deviation).

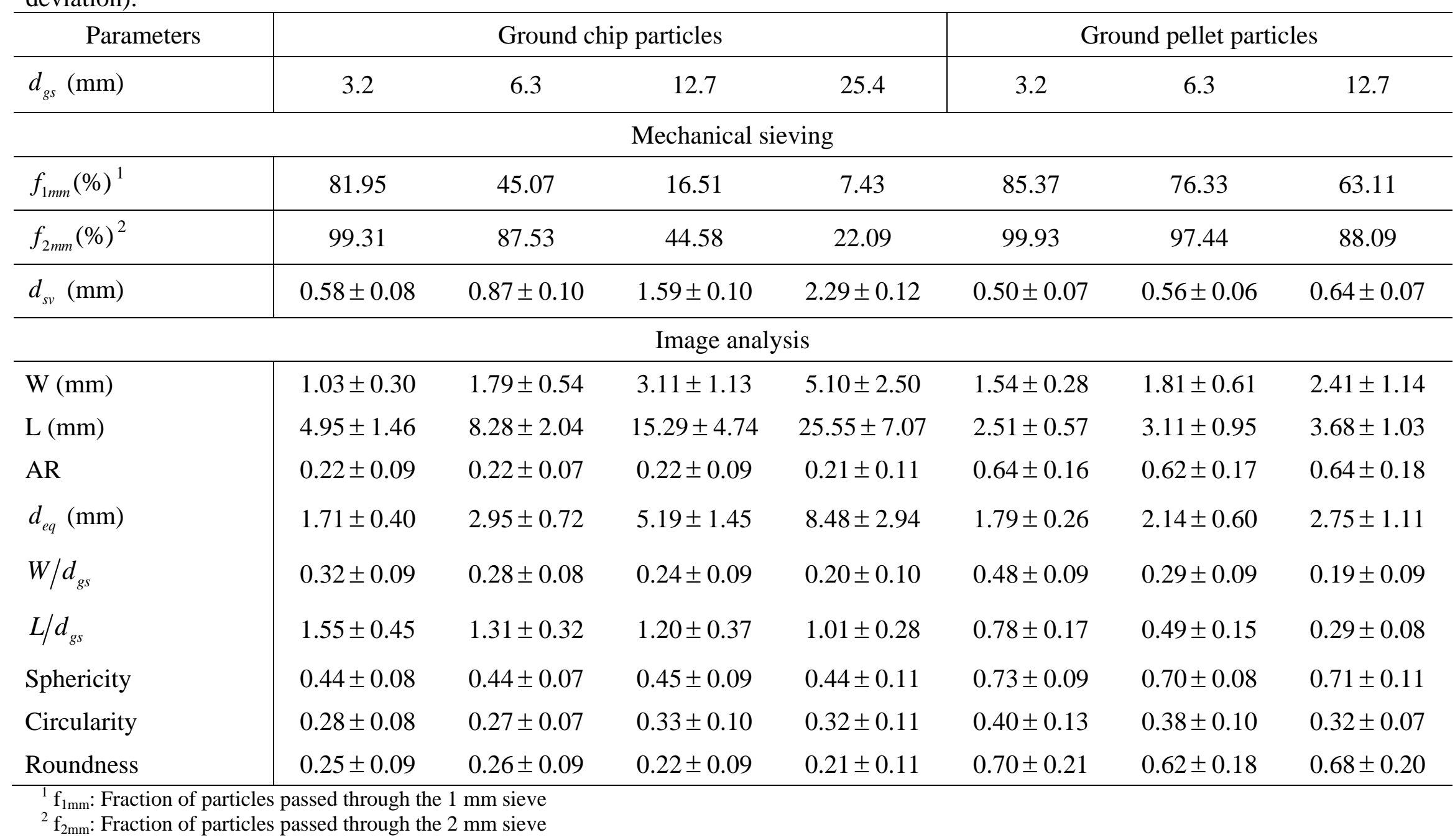


Table 3

Empirical correlations of width $(\mathrm{W}, \mathrm{mm})$, length $(\mathrm{L}, \mathrm{mm})$, mass-averaged diameter $\left(d_{s v}, \mathrm{~mm}\right)$ and equivalent spherical diameter $\left(d_{e q}\right.$, $\mathrm{mm})$ of ground chip and ground pellet particles as a function of grinder screen size $\left(d_{g s}, \mathrm{~mm}\right)$.

\begin{tabular}{|c|c|c|c|c|c|c|c|c|}
\hline \multirow{2}{*}{ Dimension (mm) } & \multicolumn{4}{|c|}{ Ground chip particles } & \multicolumn{4}{|c|}{ Ground pellet particles } \\
\hline & Correlation & $R^{2}$ & $\chi^{2}$ & RMSE & Correlation & $R^{2}$ & $\chi^{2}$ & RMSE \\
\hline Width (W) & $W=0.18 d_{g s}+0.61$ & 0.98 & 0.03 & 0.08 & $W=0.09 d_{g s}+1.23$ & 0.99 & $1.81 \mathrm{E}-4$ & 0.01 \\
\hline Length (L) & $L=0.92 d_{g s}+2.53$ & 0.99 & 0.77 & 0.12 & $L=0.12 d_{g s}+2.22$ & 0.95 & 0.03 & 0.03 \\
\hline Mass-averaged diameter $\left(d_{s v}\right)$ & $d_{s v}=0.08 d_{g s}+0.42$ & 0.95 & 0.02 & 0.05 & $d_{s v}=0.01 d_{g s}+0.46$ & 0.97 & $1.31 \mathrm{E}-4$ & 0.01 \\
\hline Equivalent spherical diameter $\left(d_{e q}\right)$ & $d_{e q}=0.30 d_{g s}+1.00$ & 0.98 & 0.11 & 0.10 & $d_{e q}=0.10 d_{g s}+1.49$ & 0.99 & $7.28 \mathrm{E}-4$ & 0.02 \\
\hline
\end{tabular}

\section{Table 4}

Flow properties of ground chip and ground pellet particles (mean \pm standard error).

\begin{tabular}{c|c|ccc|cc|c|c}
\hline \multirow{2}{*}{ Material } & \multirow{2}{*}{$d_{g s}(\mathrm{~mm})$} & \multicolumn{3}{|c|}{ Densities $\left(\mathrm{g} / \mathrm{cm}^{3}\right)$} & \multicolumn{2}{c|}{ Compressibility properties } & $\begin{array}{c}\text { Flow class } \\
(\mathrm{HR} / \mathrm{CCI})\end{array}$ & $\begin{array}{c}\text { AOR } \\
(\mathrm{degree})\end{array}$ \\
\cline { 3 - 9 } & 3.2 & $1.33 \pm 0.01$ & $0.13 \pm 0.00$ & $0.22 \pm 0.00$ & $1.57 \pm 0.01$ & $34.39 \pm 0.45$ & Poor/Poor & $61.0 \pm 1.1$ \\
& 6.3 & $1.32 \pm 0.01$ & $0.14 \pm 0.00$ & $0.21 \pm 0.00$ & $1.45 \pm 0.01$ & $31.28 \pm 0.35$ & Poor/Poor & $57.0 \pm 0.6$ \\
$\begin{array}{c}\text { Ground chip } \\
\text { particles }\end{array}$ & 12.7 & $1.26 \pm 0.01$ & $0.14 \pm 0.00$ & $0.19 \pm 0.00$ & $1.29 \pm 0.02$ & $22.67 \pm 1.33$ & Good/Fair & $52.5 \pm 0.7$ \\
& 25.4 & $1.05 \pm 0.01$ & $0.16 \pm 0.00$ & $0.19 \pm 0.00$ & $1.20 \pm 0.03$ & $16.35 \pm 2.70$ & Excellent/Good & $45.9 \pm 1.4$ \\
\hline \multirow{2}{*}{$\begin{array}{c}\text { Ground pellet } \\
\text { particles }\end{array}$} & 3.2 & $1.43 \pm 0.01$ & $0.39 \pm 0.00$ & $0.49 \pm 0.01$ & $1.27 \pm 0.03$ & $20.98 \pm 1.97$ & Good/Fair & $48.0 \pm 0.7$ \\
& 6.3 & $1.42 \pm 0.01$ & $0.40 \pm 0.00$ & $0.49 \pm 0.0$ & $1.22 \pm 0.02$ & $17.98 \pm 0.94$ & Excellent/Fair & $48.0 \pm 0.3$ \\
& 12.7 & $1.40 \pm 0.01$ & $0.42 \pm 0.00$ & $0.50 \pm 0.01$ & $1.19 \pm 0.02$ & $16.20 \pm 1.26$ & Excellent/Good & $47.6 \pm 0.3$ \\
\hline
\end{tabular}




\section{Figures:}

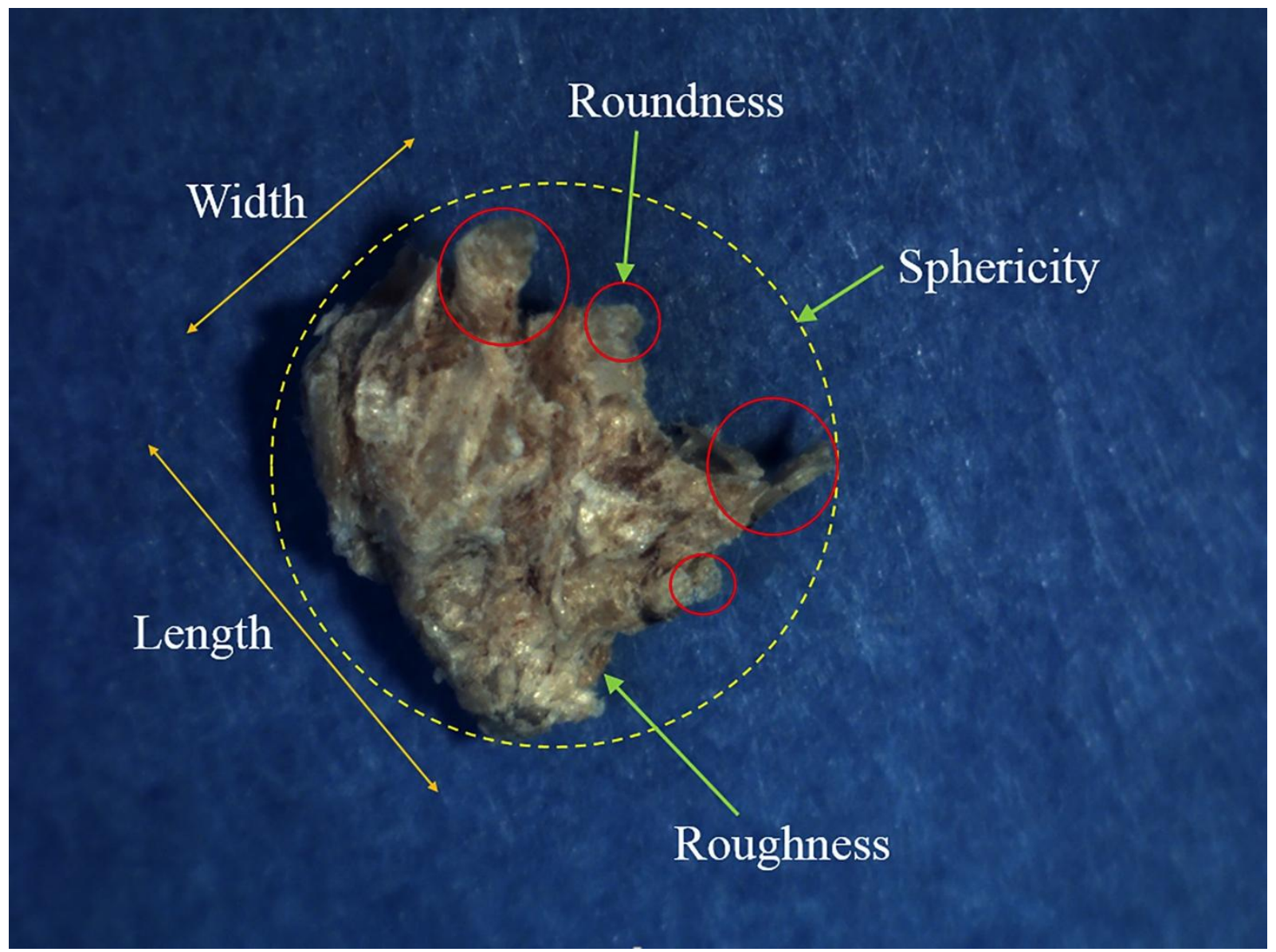

Fig. 1. Particle shape characterization in terms of dimensional ratios, sphericity, roundness and roughness. 


\section{Start}

\section{Taking pictures by:}

- Microscope: Ground chips $(3.2 \& 6.3 \mathrm{~mm}) \&$ Ground pellet $(3.2,6.3$ and $12.7 \mathrm{~mm})$

- Scanner: Ground chips (12.7 and $25.4 \mathrm{~mm}$ )

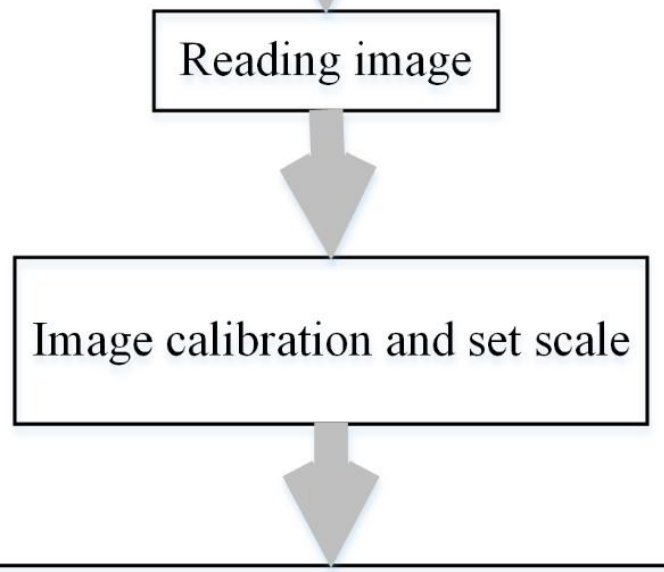

\section{ImageJ pre-processing:}

- Colored picture to grey scale stack picture (Image $>$ Type $>$ RGB Stack)

- Grey scale picture to binary (black and white) picture (Image $>$ Adjust $>$ Threshold)

\section{Image J commands:}

- Set measurements: area, perimeter, shape descriptor, fit ellipse

- Analyze $>$ Tools $>$ ROI manager

- Selecting the particle $>$ Add $>$ Measure

Fig. 2. Procedure flowchart of particle image analysis using ImageJ software. 


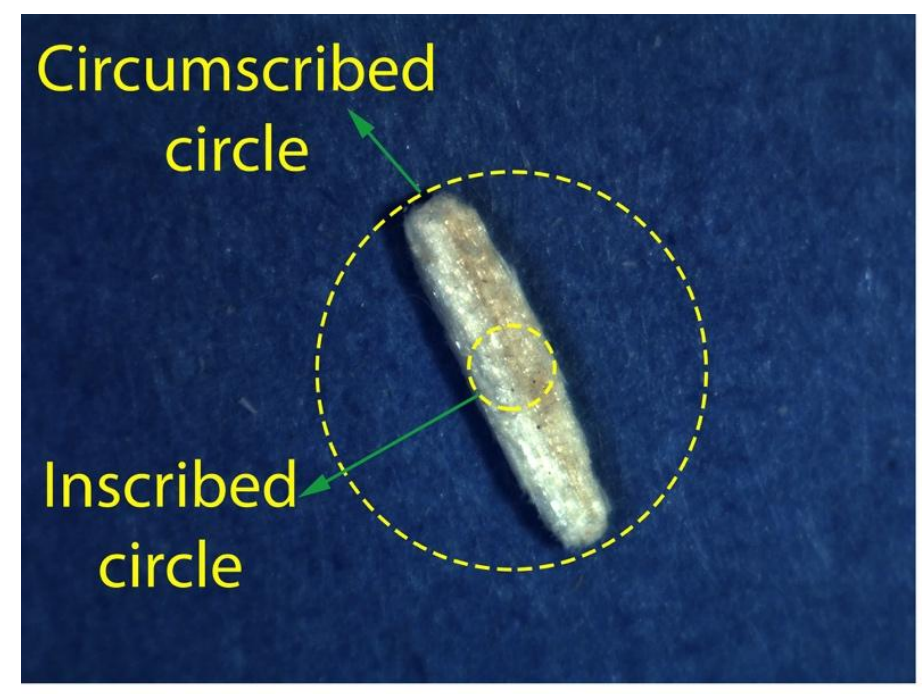

\section{Ground chip}
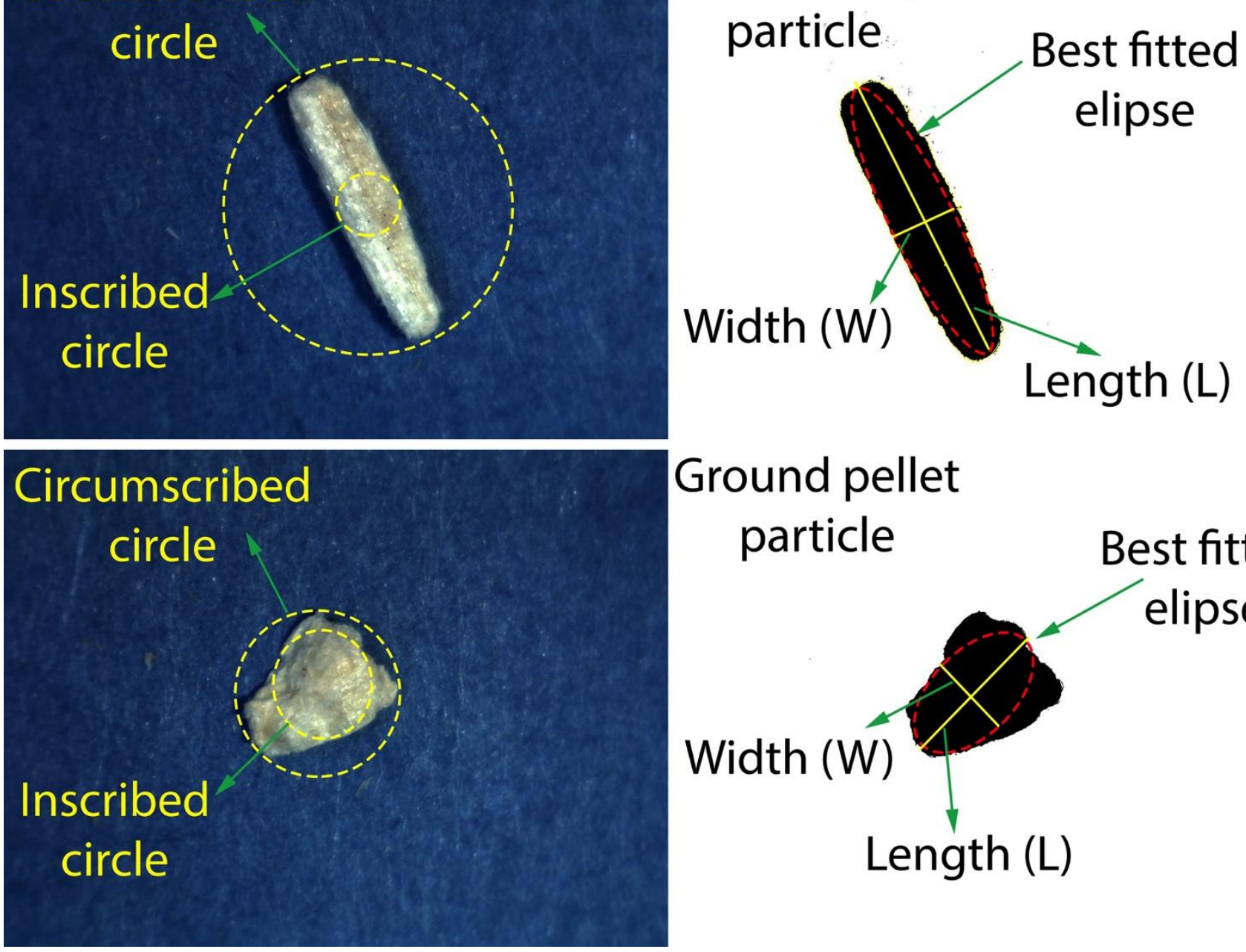

Ground pellet

particle

Best fitted

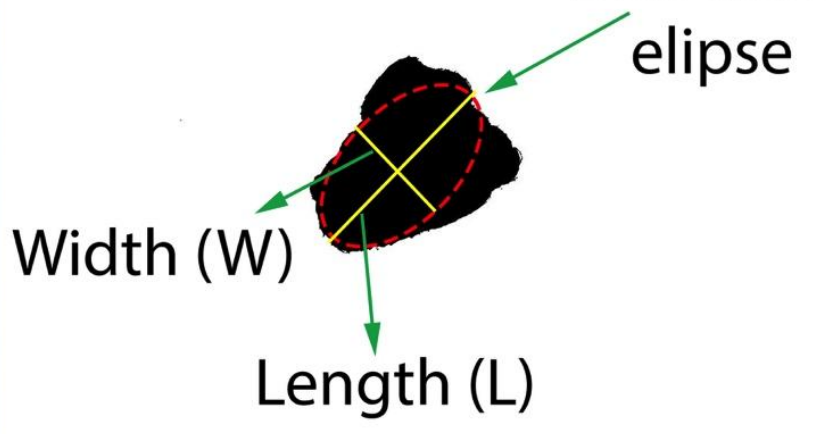

Fig. 3. Determining width (W), length (L), inscribed circle $\left(d_{C I}\right)$ and circumscribed $\left(d_{C C}\right)$ circle in a ground chip particle and a ground pellet particle. 


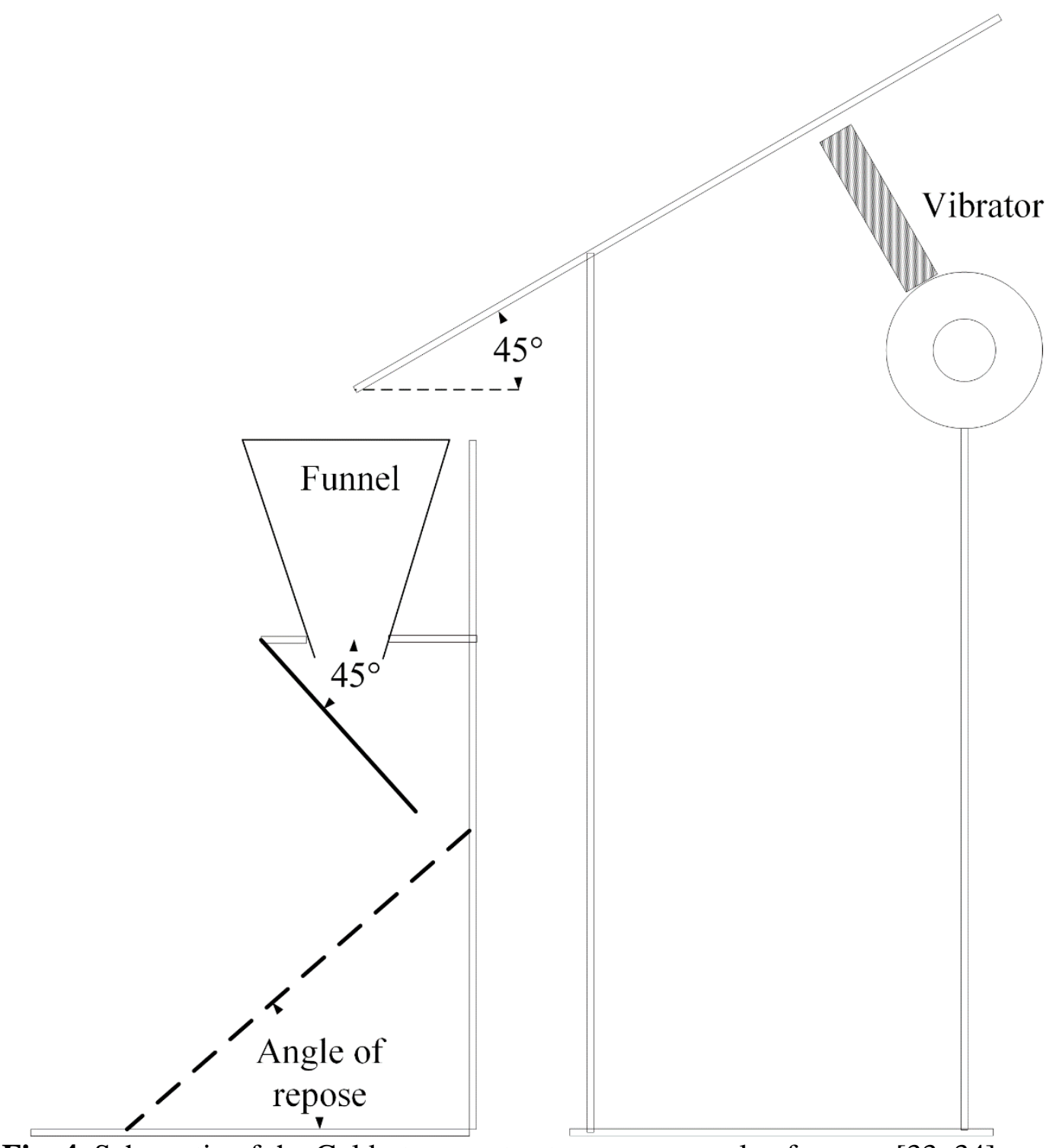

Fig. 4. Schematic of the Geldart apparatus to measure angle of repose [33, 34]. 


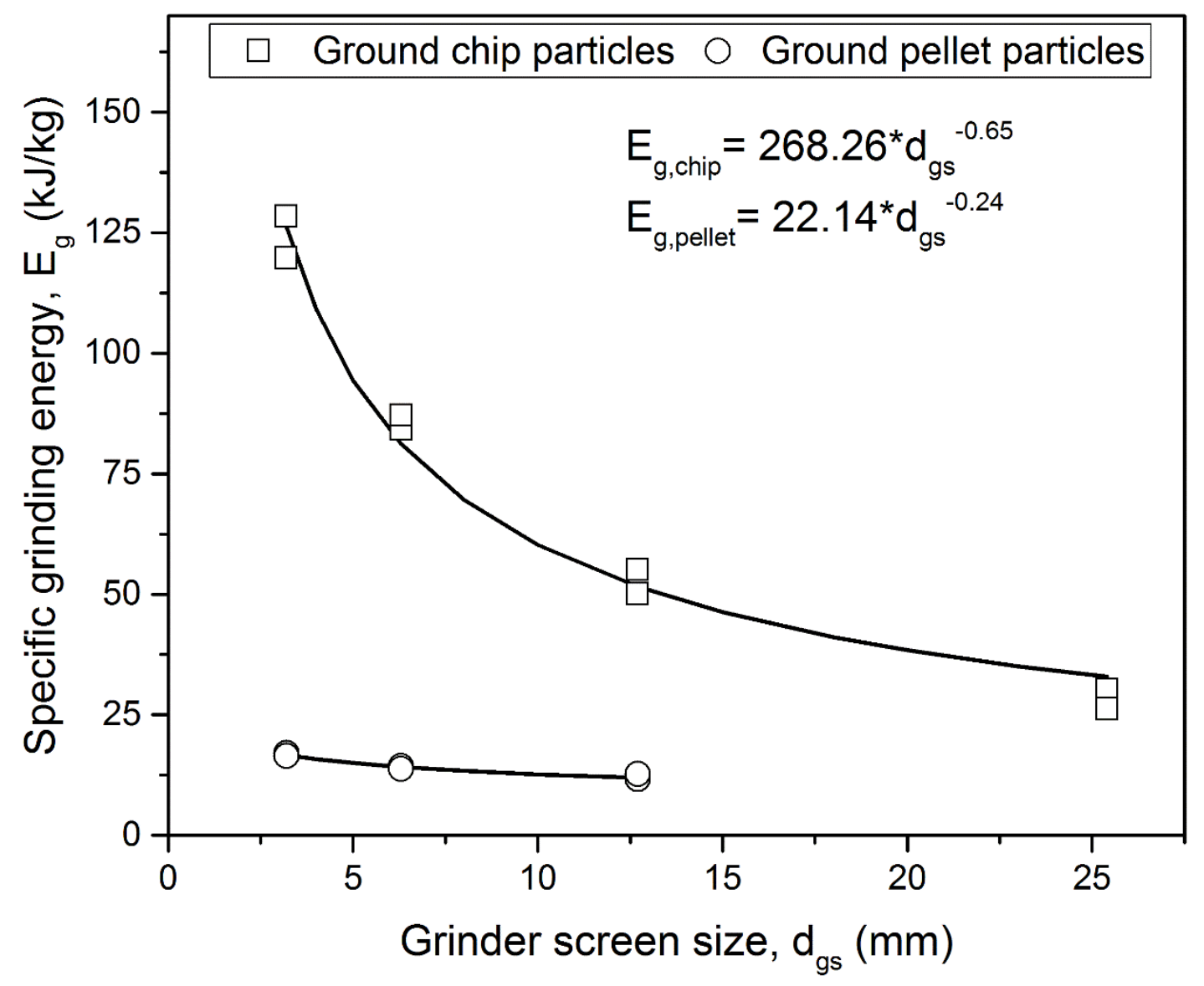

Fig. 5. Specific energy required to grind the chips and pellets using the grinder screen sizes of $3.2,6.3,12.7$ and $25.4 \mathrm{~mm}$. 

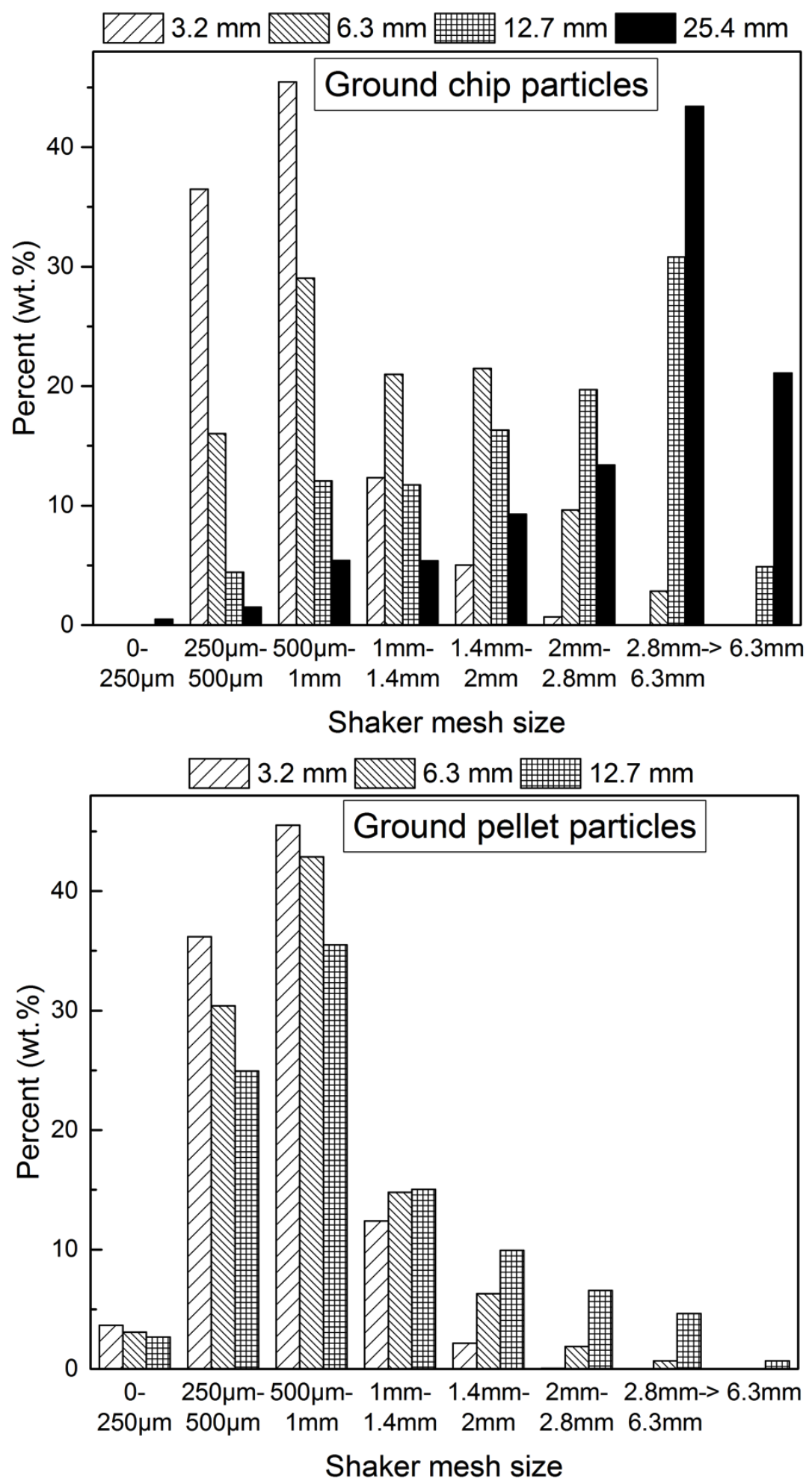

Fig. 6. Particle size distribution (PSD) of ground chip and pellet particles obtained by mechanical sieving. 


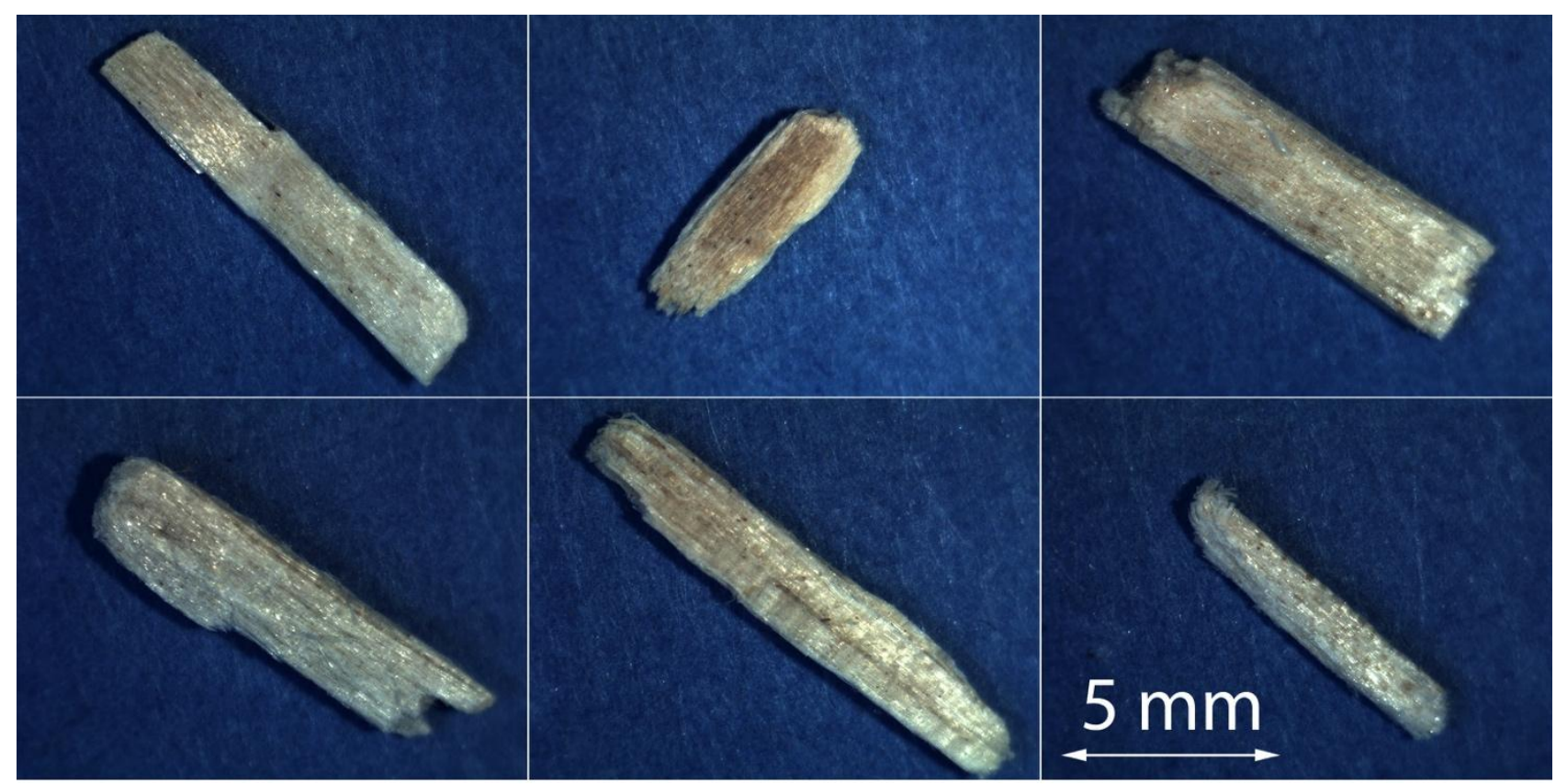

\section{Ground Chip particles}

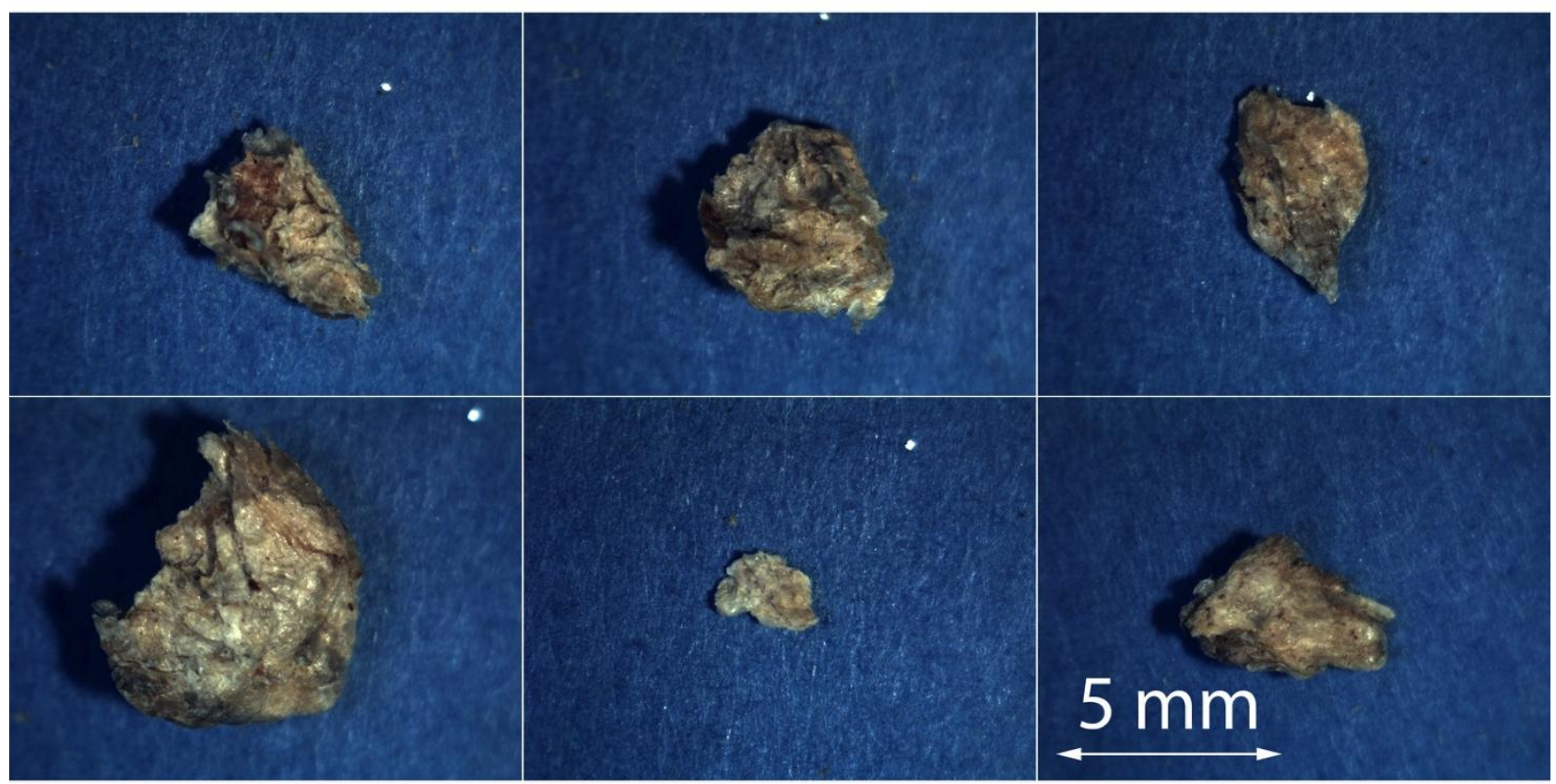

\section{Ground pellet particles}

Fig. 7. Microscopic pictures of ground chip and ground pellet particles. 

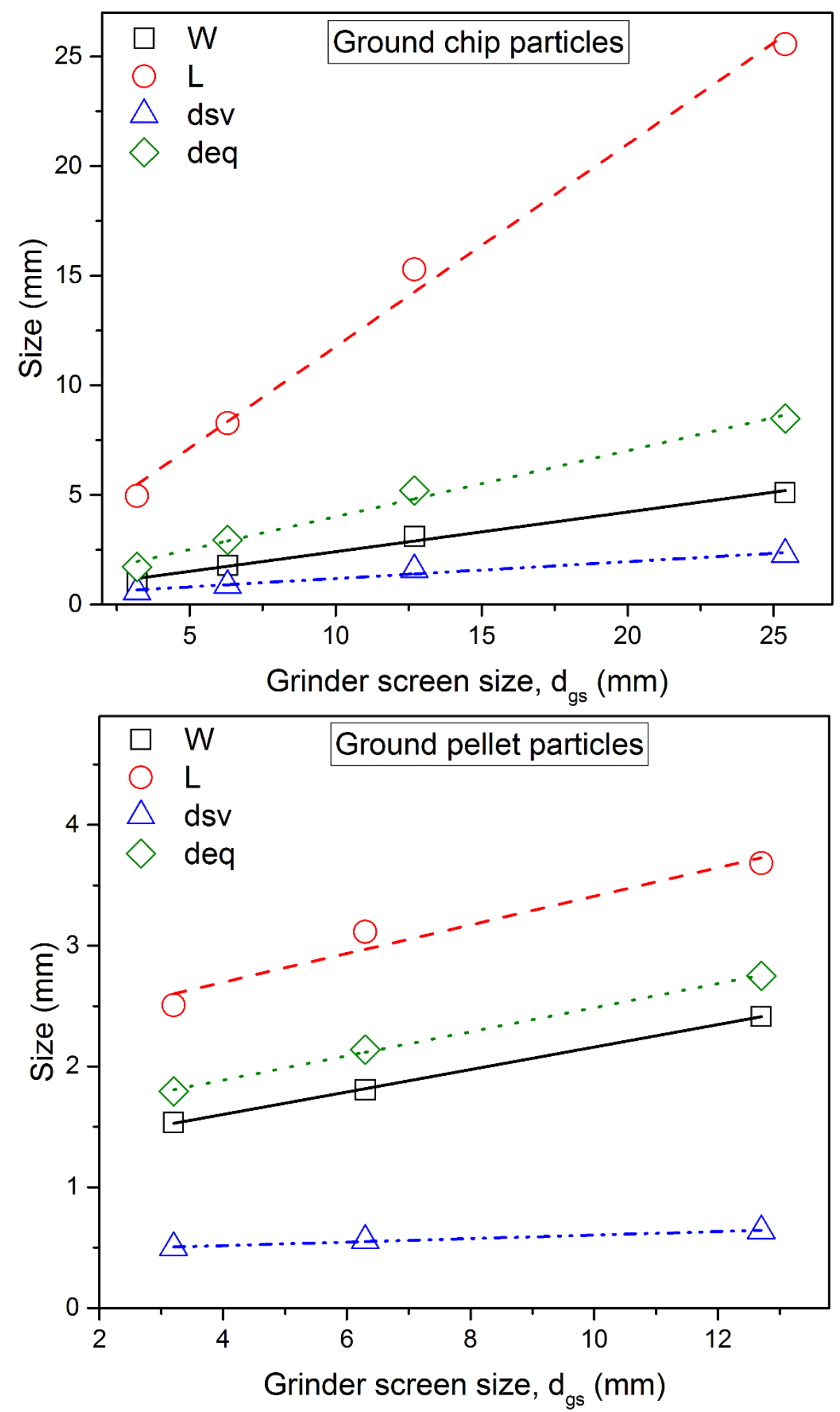

Fig. 8. Variation of average width $(\mathrm{W})$, average length $(\mathrm{L})$, mass-averaged diameter $\left(d_{s v}\right)$ and equivalent spherical diameter $\left(d_{e q}\right)$ with grinder screen size $\left(d_{g s}\right)$ for ground chip and pellet particles. 


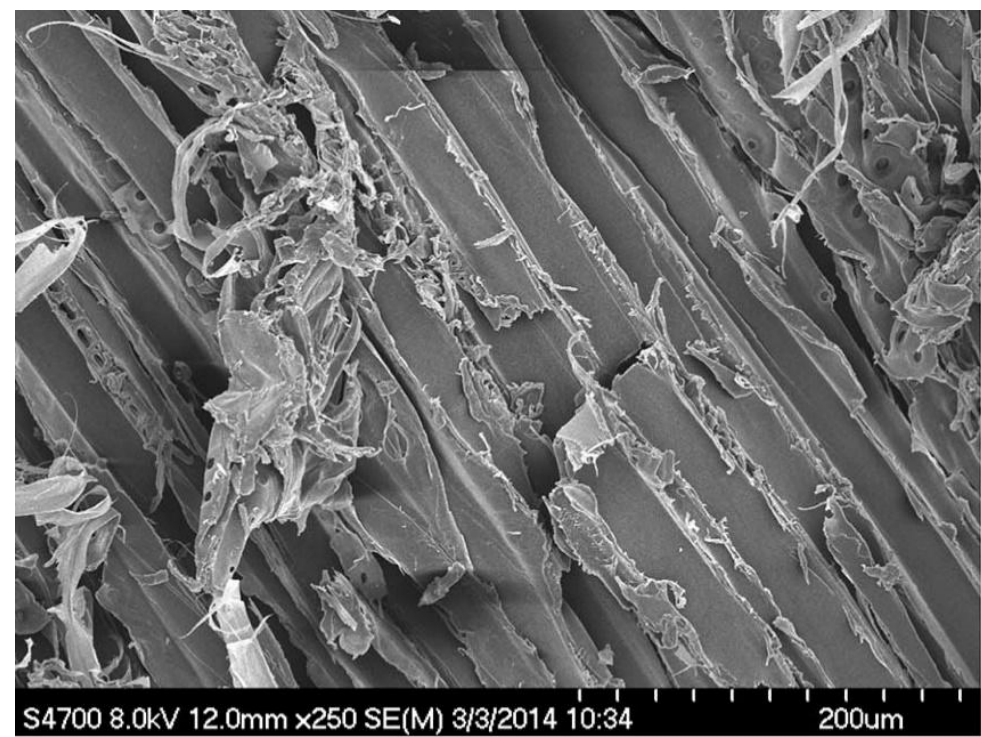

Ground chip particle

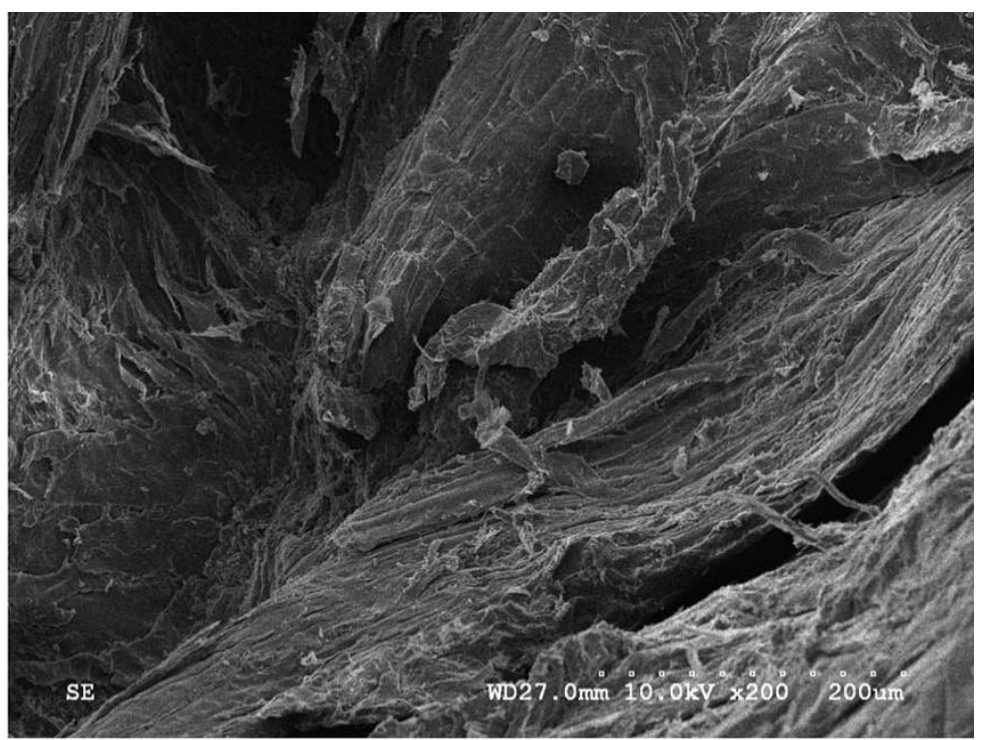

Ground pellet particle

Fig. 9. SEM images of a single ground pine chip and a single ground pine pellet particle.

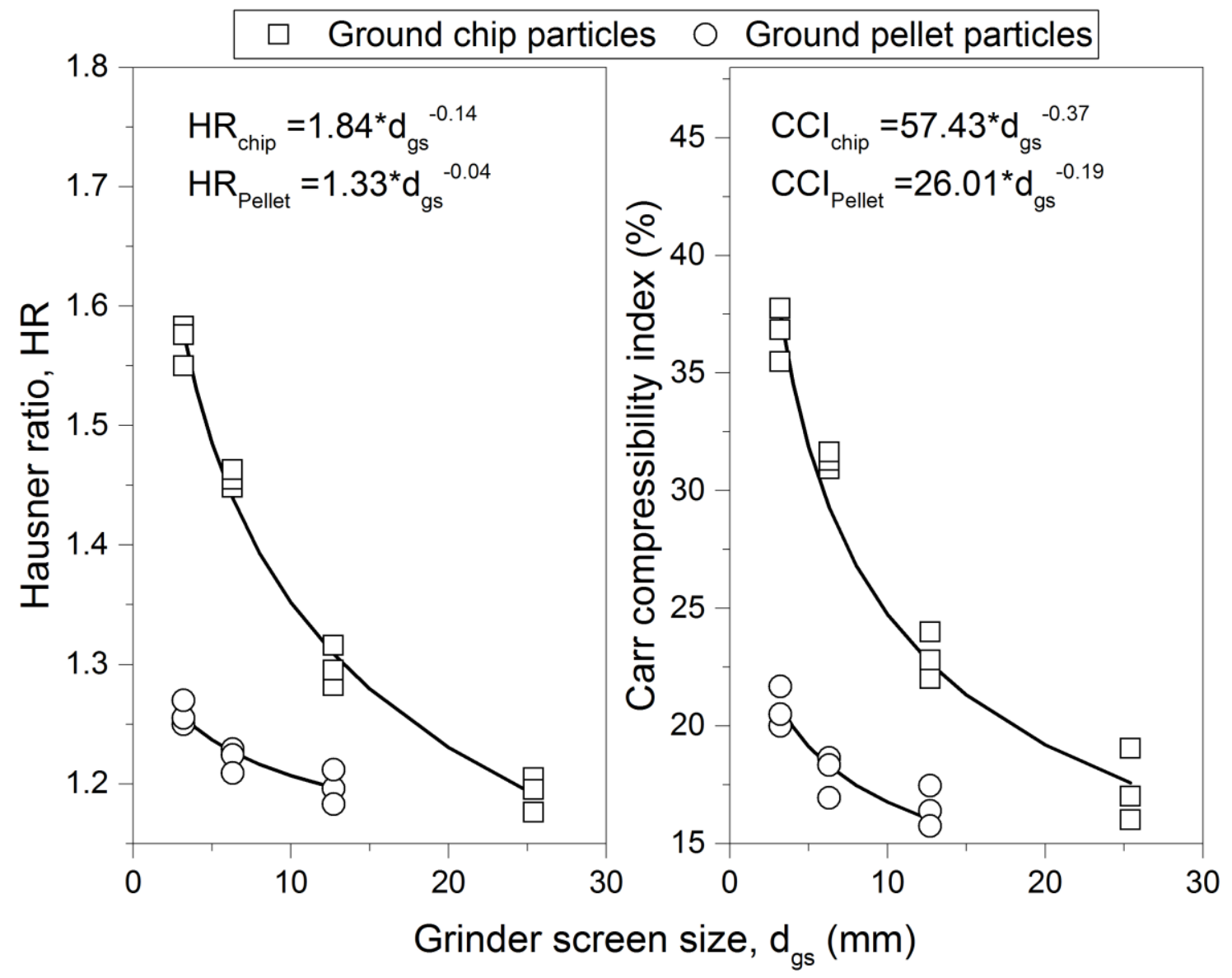

Fig. 10. Hausner ratio (HR) and Carr-compressibility index (CCI) of ground chip and pellet particles. 


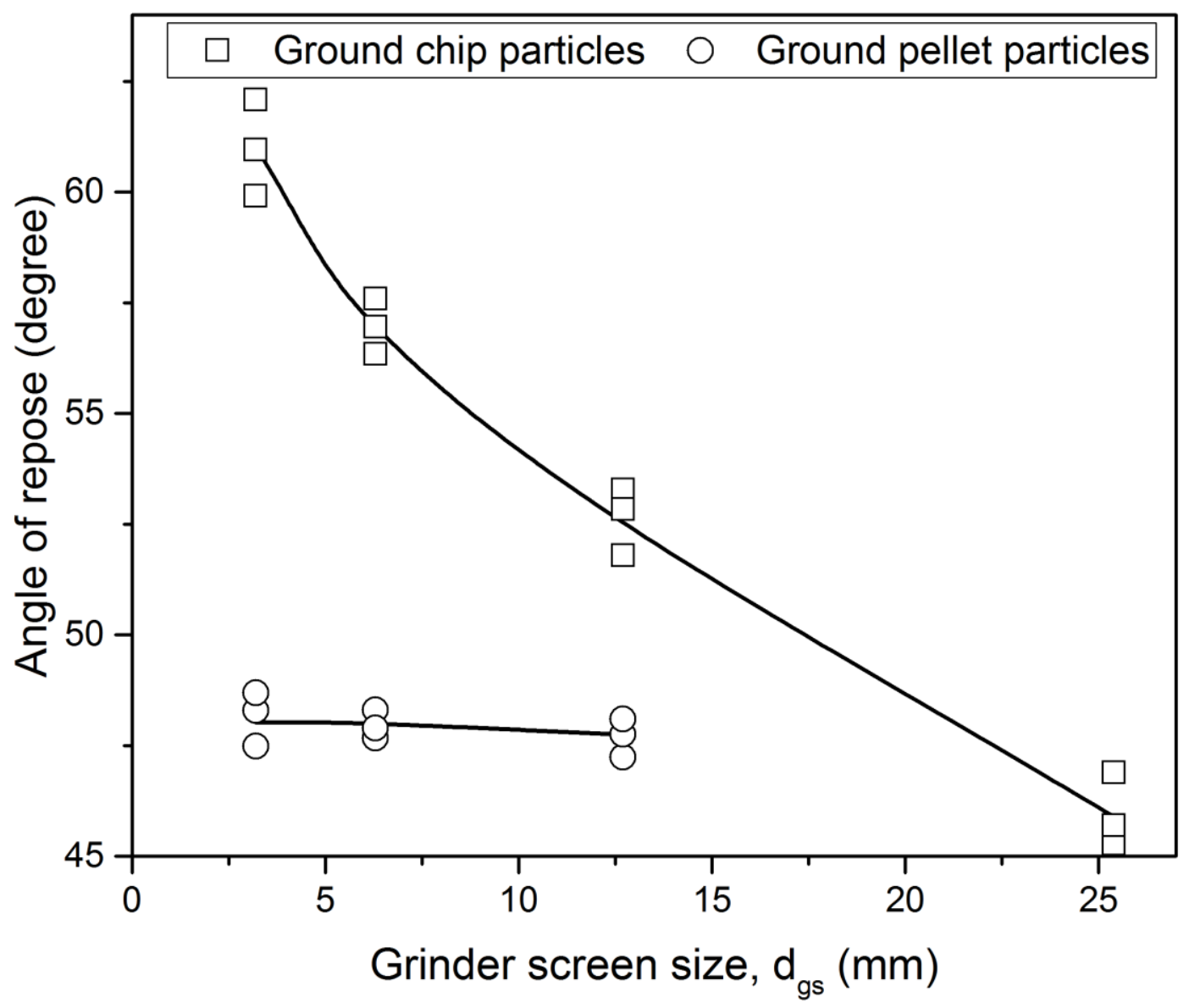

Fig. 11. Angle of repose (AOR) of ground chip and ground pellet particles. 
Circumscribed

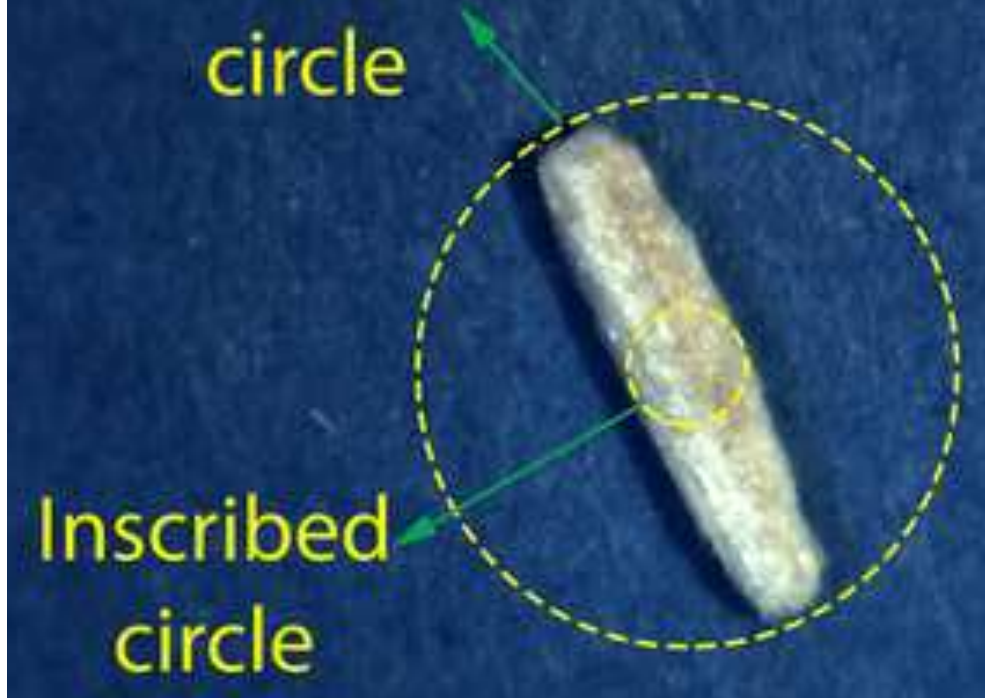

Circumscribed

circle

Inscribed

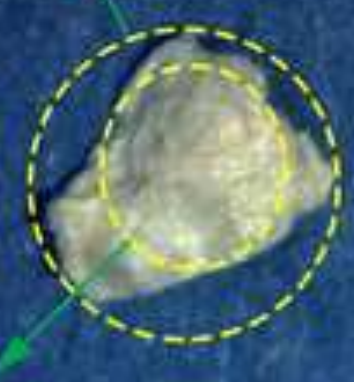

circle
Ground chip

particle

Best fitted

elipse

Width (W)

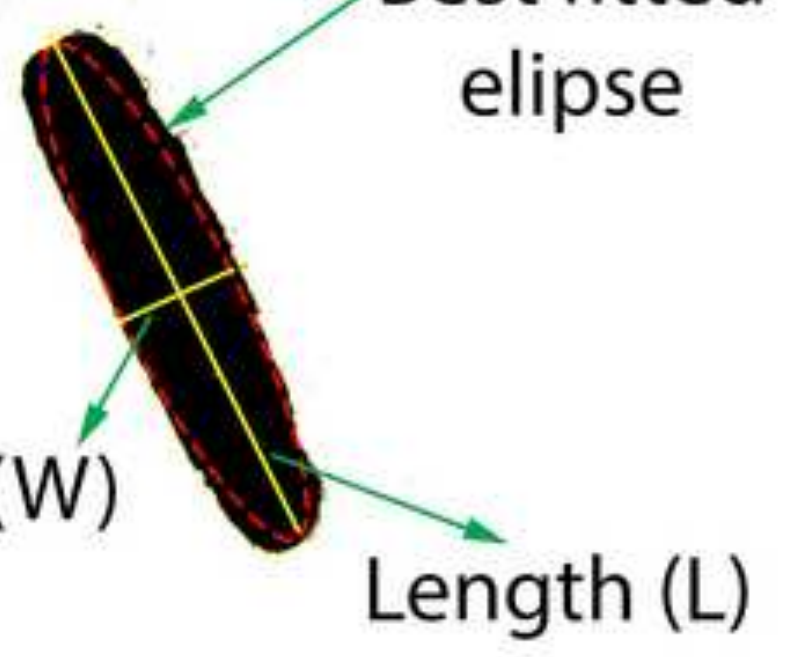

Ground pellet

particle

Best fitted

Width (W)

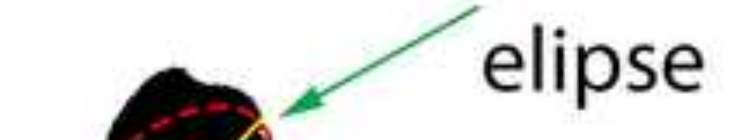

Length (L) 